\title{
A novel fungal gene regulation system based on inducible VPR-dCas9 and nucleosome map-guided sgRNA positioning
}

\author{
Andreas Schüller $^{1}$ - Lisa Wolansky ${ }^{2}$ - Harald Berger ${ }^{1}$ • Lena Studt ${ }^{1}$ - Agnieszka Gacek-Matthews ${ }^{1,3} \cdot$ Michael Sulyok $^{4}$. \\ Joseph Strauss ${ }^{1}$
}

Received: 10 July 2020 / Revised: 31 August 2020 / Accepted: 8 September 2020 / Published online: 2 October 2020

(C) The Author(s) 2020

\begin{abstract}
Programmable transcriptional regulation is a powerful tool to study gene functions. Current methods to selectively regulate target genes are mainly based on promoter exchange or on overexpressing transcriptional activators. To expand the discovery toolbox, we designed a dCas9-based RNA-guided synthetic transcription activation system for Aspergillus nidulans that uses enzymatically disabled "dead" Cas9 fused to three consecutive activation domains (VPR-dCas9). The dCas9-encoding gene is under the control of an estrogen-responsive promoter to allow induction timing and to avoid possible negative effects by strong constitutive expression of the highly active VPR domains. Especially in silent genomic regions, facultative heterochromatin and strictly positioned nucleosomes can constitute a relevant obstacle to the transcriptional machinery. To avoid this negative impact and to facilitate optimal positioning of RNA-guided VPR-dCas9 to targeted promoters, we have created a genome-wide nucleosome map from actively growing cells and stationary cultures to identify the cognate nucleosome-free regions (NFRs). Based on these maps, different single-guide RNAs (sgRNAs) were designed and tested for their targeting and activation potential. Our results demonstrate that the system can be used to regulate several genes in parallel and, depending on the VPR-dCas9 positioning, expression can be pushed to very high levels. We have used the system to turn on individual genes within two different biosynthetic gene clusters (BGCs) which are silent under normal growth conditions. This method also opens opportunities to stepwise activate individual genes in a cluster to decipher the correlated biosynthetic pathway.
\end{abstract}

\section{Keypoints}

- An inducible RNA-guided transcriptional regulator based on VPR-dCas9 was established in Aspergillus nidulans.

- Genome-wide nucleosome positioning maps were created that facilitate sgRNA positioning.

- The system was successfully applied to activate genes within two silent biosynthetic gene clusters.

Keywords dCas9 gene activation - Programmable transcriptional regulator - Aspergillus - Biosynthetic gene clusters · Genome-wide nucleosome positioning map

Electronic supplementary material The online version of this article (https://doi.org/10.1007/s00253-020-10900-9) contains supplementary material, which is available to authorized users.

Joseph Strauss

Joseph.strauss@boku.ac.at

1 Fungal Genetics Lab, Institute of Microbial Genetics, Department of Applied Genetics and Cell Biology, BOKU-University of Natural Resources and Life Sciences Vienna, BOKU-Campus Tulln, Konrad Lorenz Strasse 24, A-3430 Tulln an der Donau, Austria

2 Present address: Institute Krems Bioanalytics, IMC FH Krems University of Applied Sciences, Krems, Austria
3 Present address: Institute of Microbiology, Functional Microbiology Division, University of Veterinary Sciences Vienna, Wien, Austria

4 Institute of Bioanalytics and Agrometabolomics, Department of Agrobiotechnology, BOKU-University of Natural Resources and Life Sciences Vienna, BOKU-Campus Tulln, Konrad-Lorenz-Straße 20, A-3430 Tulln an der Donau, Austria 


\section{Introduction}

Filamentous fungi produce a plethora of metabolites and enzymes which are essential components of their response to environmental, nutritional or developmental signals. These metabolites can have beneficial but also detrimental effects on plant and animal health. In agricultural sciences, fungal research is focused on understanding the biology and genetics of phytopathogens to combat diseases and to reduce economic losses caused by product deterioration and the accumulation of toxic secondary metabolites (SMs) (Brefort et al. 2009; Hollingsworth et al. 2008). Usually, multi-gene biosynthetic gene clusters (BGCs) are responsible for the production of these SMs. These clusters show similar structures at the genomic level, always containing one or more core genes that code for backbone-generating enzymes which define the substance class of the cluster product. These backbone or signature gene(s) often code for polyketide synthases (PKSs), non-ribosomal peptide synthetases (NRPSs), prenyltransferases or terpene cyclases. Apart from the core genes, several other protein classes can be involved that serve the purpose of adding modifications, regulating gene transcription or transport of the metabolite (Brakhage 2013). Usually, the individual genes within a given BGC are transcriptionally co-regulated, not expressed by default and activated only in response to a "proprietary" expression signal. For most of these clusters, standard laboratory conditions do not generate this critical signal and consequently, their cognate products cannot be identified (Bachleitner et al. 2019; Chujo and Scott 2014; Connolly et al. 2013; Gacek-Matthews et al. 2016; Gacek and Strauss 2012; Reyes-Dominguez et al. 2010; Studt et al. 2016). About 50\% of the BGCs contain a gene that encodes a pathway-specific transcriptional activator (Keller 2019). In some cases, the expression of these transcription factors (TFs) is sufficient to orchestrate the production of the BGC product but more often overexpression of the resident TF does not upregulate the cluster (Ahuja et al. 2012; Bromann et al. 2012; Grau et al. 2018). The absence of a pathway-specific TF complicates the targeted activation of a specific cluster (Brakhage 2013; Macheleidt et al. 2016; Then Bergh and Brakhage 1998; Tilburn et al. 1995).

The number of genes that are involved in the production of SMs can vary greatly. Some SMs need only a single gene like the PKS8 in Fusarium graminearum (Westphal et al. 2018). Others need the coordinated involvement of few to many genes for the assembly of the BGC product like the asperthecin cluster of Aspergillus nidulans which comprises 3 genes (Szewczyk et al. 2008) or the sterigmatocystin cluster of A. nidulans which consists of 25 genes (Brown et al. 1996). Genomes of filamentous fungi contain a large number and diversity of BGCs. It is well established that the repression of SM BGCs can comprise a multitude of global but also specific regulators that act on the maintenance of a repressive chromatin structure, influence signal transduction pathways or impact gene expression by post-translational modifications or processing of regulators (Brakhage 2013;
Brakhage and Schroeckh 2011; García-Estrada et al. 2018; Gerke and Braus 2014; Keller 2019; Lyu et al. 2020; ReyesDominguez et al. 2010; Romsdahl and Wang 2019). Therefore, the products of many silent SM BGCs remain elusive. For activation of cryptic clusters in fungi, a plethora of methods was already applied. They comprise promoter replacements in cis (Ahuja et al. 2012; Chiang et al. 2010; Lin et al. 2019; Wiemann et al. 2018; Yeh et al. 2016), the expression of hybrid transactivators (Grau et al. 2018), overexpression or deletion of cluster-specific and global regulators (Bachleitner et al. 2019; Bok et al. 2006, 2009; Chiang et al. 2010; Gacek-Matthews et al. 2016; Grau et al. 2019; Niehaus et al. 2016b; Oakley et al. 2017; Szewczyk et al. 2008), interference with chromatin-based silencing (Bok et al. 2009, 2013; Connolly et al. 2013; GacekMatthews et al. 2016; Niehaus et al. 2016b; Reyes-Dominguez et al. 2010; Studt et al. 2013, 2016; Westphal et al. 2019), protein stabilisation (Gerke et al. 2012), trans-expression of whole BGCs in a heterologous host (Clevenger et al. 2017) and approaches based on the variation of cultivation conditions (i.e. "OSMAC") including the cocultivation with other organisms (Bode et al. 2002; Nützmann et al. 2011; Scherlach et al. 2011; Schroeckh et al. 2009). In case of the model fungus A. nidulans, these methods where successful in deciphering the biosynthetic pathways of 32 of its approximately 64 clusters (Ahuja et al. 2012; Andersen et al. 2013; MacCabe et al. 1991; Bergmann et al. 2007; Bok et al. 2006, 2009; Bromann et al. 2012; Brown et al. 1996; Chiang et al. 2008, 2009, 2016; Eisendle et al. 2003; Gerke et al. 2012; Grau et al. 2018; Hai et al. 2019; Ishikawa et al. 2014; Lin et al. 2019; Lo et al. 2012; Macheleidt et al. 2016; Romsdahl and Wang 2019; Sanchez et al. 2010, 2011, 2012; Sung et al. 2017; Szewczyk et al. 2008; Watanabe et al. 1999; Yaegashi et al. 2013; Yeh et al. 2012, 2016). The same is true for other fungi such as Fusarium spp. (Hansen et al. 2015; Niehaus et al. 2016a; Wiemann et al. 2013), Penicillium sp. (Nielsen et al. 2017) and Sclerotinia sclerotiorum (Graham-Taylor et al. 2020).

Due to the recent revolution in sequencing techniques, the complete genome sequence of over 700 different fungal species has been determined so far (https://mycocosm.jgi.doe.gov). This theoretically represents an enormously rich resource for novel bioactive compounds (Nordberg et al. 2014). Many fungi however have very low homologous recombination rates which makes gene targeting in situ very inefficient and laborious. This complicates the genetic manipulation of these species and slows down the revelation of novel compounds. Furthermore, already established methods cannot be used for the activation of any given BGC type. Promoter exchanges seem only practical with small predicted clusters or clusters that harbour a clear candidate of BGC-specific TF that can be overexpressed and converted to its active state. For BGCs that do not contain a TF or contain a TF that requires specific post-translational modifications for activity, this approach will not be successful. In A. nidulans, Yeh et al. (2016) and Lin et al. (2019) conducted serial promoter exchanges and thereby successfully elucidated the synthesis of fellutamide B 
(six promoter replacements) and aspernidgulenes (four promoter replacements). BGCs can however contain many more genes, like the sterigmatocystin cluster which consist of around twenty-five genes (Brown et al. 1996). Promoter exchange experiments, although shown to be successful on small clusters, are however often laborious and require selection marker recycling strategies (e.g. Cre/loxP) (Aguiar et al. 2014). Another problem that emerges during promoter exchange studies is the integrity of the transformation locus. Fungi like Aspergillus spp. and Fusarium spp. have a high gene density ( $\sim 1$ gene/3000 bps (Bashyal et al. 2017; Cuomo et al. 2007; Galagan et al. 2005)) when compared with other eukaryotes like human $(\sim 1$ gene/150,000 bps (Ezkurdia et al. 2014; Piovesan et al. 2019)), Mus musculus ( 1 gene/83,000 bps (Weitzman 2002)), Caenorhabditis elegans $(\sim 1$ gene/5000 bps (Consortium 1998)), Drosophila melanogaster $(\sim$ 1 gene/9000 bps (Adams et al. 2000)), Arabidopsis thaliana $(\sim 1$ gene/5000 bps (Arabidopsis Genome 2000)) or Oryzae sativa ( 1 gene/9500 bps (Kawahara et al. 2013)). Thus, many control elements (promoters, terminators, binding motifs, etc.) in filamentous fungi like $A$. nidulans are in near vicinity to each other. Interfering with the integrity of the genomic locus could lead to unforeseen consequences on neighbouring genes, cis- or trans-regulatory elements and the chromatin structure at this locus.

Apart from promoter replacement approaches, hybrid transactivators were tested for activation. By fusing the DNA-binding domain of the cluster-specific TF from a gene residing in the (+)-Asperlin BGC with an activation domain of another transcriptional activator (i.e. AfoA), the cluster could be activated and the cognate product was identified (Grau et al. 2018). Again, this approach can only be successful if the BGC in question contains also a specific TF.

Other approaches that interfere with chromatin-based regulators, such as histone deacetylases (Shwab et al. 2007; Studt et al. 2013), heterochromatin protein 1 (Reyes-Dominguez et al. 2010), histone methyl transferases (Chujo and Scott 2014; Connolly et al. 2013; Studt et al. 2016) or histone demethylases (Bachleitner et al. 2019; Gacek-Matthews et al. 2016), also do not work for all BGCs as some are upregulated by chromatin engineering but others are repressed by the same changes. Furthermore, this approach cannot be used for targeting only a specific cluster. Modification of chromatin may not only have effects on BGCs, but can also influence primary metabolism and developmental processes.

Because of these complications and limitations of established techniques, there are still a great number of fungal species that await the deciphering of their predicted BGCs and the characterisation of their cognate metabolite (Lyu et al. 2020). Here, we present a new method to activate silent genes which is based on the expression and precise targeting of a synthetic activator composed of an enzymatically disabled "dead" Cas9 (dCas9) fused to three consecutively arranged strong activation domains termed V-P-R. The whole dCas9-VPR system was already described to function in human cell lines by Chavez et al. (2015). In the tripartite activation domain, "V" represents 4 copies of the VP16 domain of the Herpes Simplex Virus (i.e. VP64), "P" stands for a part of the p65 domain of the human transcription factor NF-KB and "R" represents a segment of the Rta transactivator of the Epstein-Barr virus. Each of these activator domains have been extensively studied and shown to individually enhance or facilitate gene activation by engaging in different protein interactions within the transcriptional machinery (Chang et al. 2005; Hall and Struhl 2002; Hardwick et al. 1992; Lecoq et al. 2017; Lee and Hahn 1995; Schmitz and Baeuerle 1991). We centred our approach on a dCas9-based gene activation system because with this, the activator can be targeted at one or more genomic locations easily and simultaneously simply by expressing the right combination of guide RNAs. Moreover, the functionality of the conventional CRISPR/Cas9 system for genetic manipulation of a single site or multiple loci (multiplex sgRNAs) is firmly established in A. nidulans and other filamentous fungi as reviewed by Song et al. (Nødvig et al. 2018; Song et al. 2019). We reasoned that VPR-dCas9 can be expressed in the host and guided by co-expressed sgRNAs to any accessible locus in the genome. By expression of one or more sgRNAs in the VPR-dCas9-containing strain, one or more individual genes in different combinations can be targeted and activated in a predicted BGC. This also provides the opportunity to stepwise activate different genes within a target BGC that may lead to the discovery of a novel metabolite and its intermediates. As this system does not require in loco transformation at the BGC of interest, it can be applied as ectopic construct or as an episomal plasmid by utilising the AMA1 region of $A$. nidulans. This would make it applicable in various other species as well which do not support fast and efficient in loco transformations. The functionality of the A. nidulans AMA1 region was already verified in several other fungal species which makes this a very promising option for introducing the VPR-dCas9 activator system into other species (Bok et al. 2015; Brückner et al. 1992; Kubodera et al. 2002; Rebordinos et al. 2000; Shimizu et al. 2012).

Here, we detail the methodology and provide proof-ofconcept for functionality of the VPR-dCas9 system by targeting BGCs that are involved in the production of monodictyphenone ( $m d p)$ and prenylated xanthones (Chiang et al. 2010; Sanchez et al. 2011), as well as two genes in a predicted cluster for which the cognate product is not known yet.

\section{Materials and methods}

\section{Plasmid generation}

Plasmids were constructed by means of DNA restriction digests, polymerase chain reactions (PCRs) and subsequent ligation by yeast recombinational cloning (YRC) (Schumacher 2012). All oligos were acquired from Sigma-Aldrich ("DNA Oligos in Tubes"; St. Louis, MO, USA). For YRC, overlap 
extension PCRs were used for creating fragments with homologous overhangs ( $\geq 20$ nucleotides). The backbone plasmid was $p$ RS426 (Christianson et al. 1992) and the yeast strain for transformation was the uracil-auxotrophic strain FGSC 9721 (FY 834) (Winston et al. 1995). Five microliters of each PCR fragment were used for YRC. After YRC, the purified plasmids (New England Biolabs; Ipswich, MA, USA; Monarch ${ }^{\circledR}$ Plasmid Miniprep Kit; Art. No.: T1010S) were verified by sequencing ("Ready2Run" by LGC Genomics $\mathrm{GmbH}$; Berlin, Germany). All plasmids that have been generated and used in that study are summarised Table 1. All fragments and the corresponding primers are listed in Supplementary Table S1.

For generation of $p$ VPR 4 (for plasmid map, see Fig. 1a; the number indicates the laboratory internal plasmid version), the backbone vector $p$ RS426 was digested with EcoRI and $X h o I$ over night at $37^{\circ} \mathrm{C}$ in $2 \times$ Tango buffer (Thermo Fisher Scientific ${ }^{\mathrm{TM}}$; Waltham, MA, USA; Art. No.: ER0271, ER0691) and directly used for YRC. Together with the digest, following DNA fragments were used for transformation of yeast strain FY834 (for primer pairs, see Supplementary Table S1). The gene of the human estrogen receptor alpha $(h E R)$ was amplified by primer pair hER-F/R (template source: phERpyr4 (Pachlinger et al. 2005)), which is under the control of the constitutive coxA promoter (Sarkari et al. 2017) which was amplified by primer pair P.coxA-1-F/R and P.coxA-2-F/R (template source: genomic DNA from Aspergillus niger wild-type isolate (in-house strain collection AIT-\#931)) and the terminator region of the tef1 orthologue of A. niger (An18g04840) which was amplified by primer pair T.tefl-1-F/R (template source: genomic DNA from A. niger wild-type isolate (inhouse strain collection AIT-\#931)). The VPR-dCas 9 fusion was amplified from two different sources. VPR was amplified by primer pair $V P R-\mathrm{F} / \mathrm{R}$ (template source: $\mathrm{pWalium} 20$ -

Table 1 Plasmids. Plasmid names, the most important elements and the backbone plasmid are shown. Consecutive numbers in the plasmid name (i.e. $\mathrm{m} 1-\mathrm{m} 4$ and A1-A2) indicate different sgRNAs. Targeted genes are shown under elements in parenthesis. Elements comprise the human estrogen receptor gene (hER), the activator VPR-dCas9, the selection markers (i.e. $\operatorname{argB}$ or pyroA) and the different sgRNA cassettes

\begin{tabular}{lll}
\hline Plasmid & Elements & Backbone \\
\hline$p$ VPR4 & $h E R$, VPR-dCas9, $\arg B$ & $p$ RS426 \\
$p$ sgRNA & sgRNA scaffold, pyroA & $p$ RS426 \\
$p$ sgRNA-m1 & sgRNA-m1 $(m d p E)$, pyroA & $p$ sgRNA \\
$p$ sgRNA-m2 & sgRNA-m2 $(m d p E)$, pyroA & $p$ sgRNA \\
$p$ sgRNA-m3 & sgRNA-m3 $(m d p E)$, pyroA & $p$ sgRNA \\
$p$ sgRNA-m4 & sgRNA-m4 $(m d p E), p y r o A$ & $p$ sgRNA \\
$p$ sgRNA-A1 & sgRNA-A1 (AN8506), pyroA & $p$ sgRNA \\
$p$ sgRNA-A2 & sgRNA-A2 (AN8507), pyroA & $p$ sgRNA \\
\hline
\end{tabular}

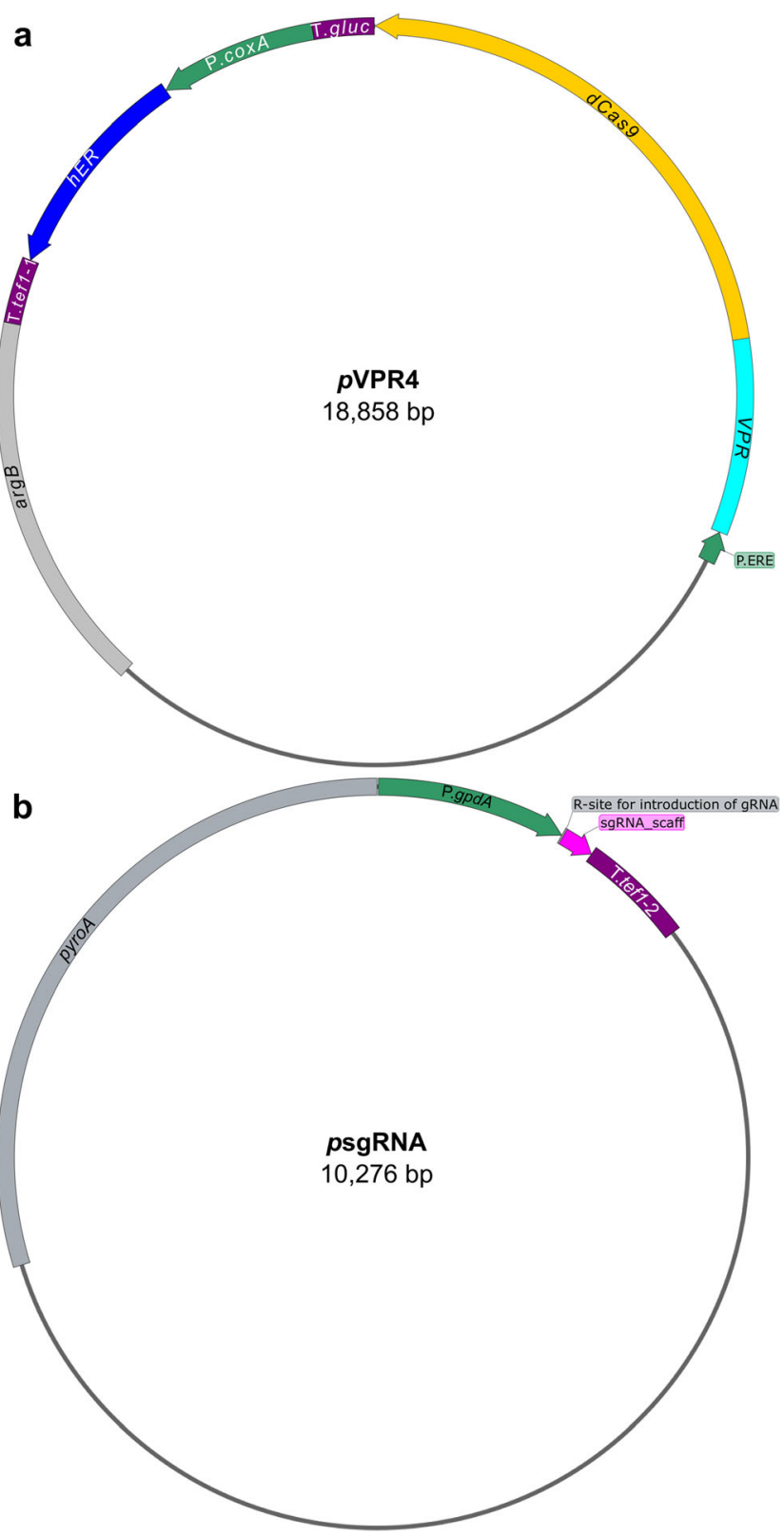

10XUAS-3XFLAG-dCas9-VPR (Addgene No.: \#78897) (Lin et al. 2015)) while $d C a s 9$ was amplified by primer pair $d$ Cas $9-1-\mathrm{F} / \mathrm{R}$ and $d$ Cas $9-2-\mathrm{F} / \mathrm{R}$ (template source: pCAG$B i r *^{*}-d C a s 9-e G F P$ which was kindly provided by the Leonardt laboratory (Schmidtmann et al. 2016)). The estrogen response elements which represent the promoter of the $V P R-d C a s 9$ fusion gene were amplified by primer pair P.ERE-F/R (template source: pJW52_[3xERE-RS$\mathrm{P}($ nirA)]-[hER-trpC]-[pyro3/4] (Bödi 2008)). The terminator of VPR-dCas 9 originates from the glucanase gene of Botrytis cinerea and was amplified by primer pairs T.glucF/R (template source: pNAH-PoliC::bcltf3-gfp (Brandhoff et al. 2017)). For selection of transformants, the whole $\arg B$ gene (including promoter and terminator region) from A. nidulans was used as auxotrophy marker which was 
Fig. 1 Schematic drawing of plasmids encoding the components of the VPR-dCas9 activation system. Selection markers for fungal transformation are depicted in grey, promoters in green and terminators in purple. a Plasmid VPR4 carries the gene for the activator VPR-dCas9 (cyan, yellow) which has a synthetic promoter containing estrogen response elements (EREs) as binding motif for the human estrogen receptor (hER). The terminator of $V P R-d \operatorname{Cas} 9$ is derived from the glucanase gene of Botrytis cinerea. The $h E R$ gene (blue) is transcribed constitutively by the coxA promoter from Aspergillus niger and termination is controlled by the terminator region of the tef1 orthologue of $A$. niger. The produced hER protein remains transcriptionally inactive unless it is converted to an active form (i.e. homodimer formation) by the addition of estrogens (i.e. DES). The selection marker $\arg B$ is originated from $A$. nidulans. b Plasmid sgRNA is the parent vector of all sgRNA-carrying plasmids. It carries the sgRNA scaffold (magenta) which consists of the tracrRNA and HDV ribozyme. Directly upstream of the tracrRNA sequence an Eco91I restriction site is introduced for insertion of the specific gRNA sequences together with the hammerhead ribozyme. After insertion, both elements combined form the functional sgRNA cassette which releases the functional sgRNA upon transcription. The sgRNA cassette is constitutively expressed by the gpdA promoter of $A$. fumigatus and terminated by the terminator of the tefl gene of A. fumigatus. The selection marker pyroA originates from A. fumigatus. Detailed information about the plasmids and their construction can be retrieved from section "Plasmid generation". Figure was generated by SnapGene ${ }^{\circledR}$ software (from GSL Biotech; available at snapgene.com)

amplified by primer pair $\arg B-\mathrm{F} / \mathrm{R}$ (template source: gDNA of A. nidulans WIM 126 (Mooney and Yager 1990)).

For the generation of $p \operatorname{sgRNA}$ (Fig. 1b) and subsequent plasmids (i.e. $p$ sgRNA carrying a sgRNA), $p$ RS426 was digested with NdeI (Thermo Fisher Scientific ${ }^{\mathrm{TM}}$ : Art. No.: ER0581). Together with the digest, following DNA fragments were used for transformation of FY834 (see Supplementary Table S1 for information about primers). The missing part of the URA3 marker (disrupted by $N d e \mathrm{I}$ ) was amplified by primer pair $U R A 3-\mathrm{F} / \mathrm{R}$ as well as the $2 \mu$-ori which was amplified by primer pair $2 \mu$-ori-F/R (template source: $p \mathrm{RS} 426$ (Christianson et al. 1992)). The plasmid furthermore contains the sgRNA cassette which was amplified by primer pair sgRNAscaff-F/R (template source: pFC334 (Nødvig et al. 2015), which was kindly provided by the Mortensen laboratory). The promoter for the sgRNA cassette is from the $g p d A$ gene and was amplified by primer pair P.gpdA-F/R (template source: gDNA from Aspergillus fumigatus wild-type isolate (in-house strain collection AIT-\#1232)) while the terminator was from the tefl gene and was amplified by primer pair tef12-F/R (template source: gDNA of A. fumigatus wild-type isolate (in-house strain collection AIT-\#1232)). pyroA (including promoter and terminator) from A. fumigatus was used as auxotrophy marker for selection of transformants and was amplified by primer pair pyroA-F/R (template source: gDNA of A. fumigatus wild-type isolate (in-house strain collection AIT-\#1232)).

For the insertion of sgRNAs into $p \operatorname{sgRNA}$ (i.e. generation of plasmids $p \operatorname{sgRNA}-\mathrm{m} 1$ to $\mathrm{m} 4$ and $p \operatorname{sgRNA}-\mathrm{A} 1$ and A2), the plasmid was digested by Eco91I (Thermo Fisher Scientific ${ }^{\mathrm{TM}}$ :
Art. No.: ER0392). The digested plasmid was then used together with $2 \mu \mathrm{L}$ of the respective annealed gRNA oligonucleotides for transformation of FY834. For annealing of the forward and reverse gRNA oligonucleotide (Supplementary Table S2), both were dissolved in annealing buffer (final concentrations: $10 \mathrm{mM}$ Tris, $\mathrm{pH} 7.5,50 \mathrm{mM} \mathrm{NaCl}, 1 \mathrm{mM}$ EDTA, $100 \mu \mathrm{M}$ of each oligonucleotide). The DNA was subsequently denaturised by heating the mix up to $95{ }^{\circ} \mathrm{C}$ for $5 \mathrm{~min}$ in a Thermocycler (Analytic Jena AG; Jena, Germany; Biometra, Thermocycler, Art. No.: T3000-48) followed by an annealing step by cooling the mix down to $25^{\circ} \mathrm{C}$ at $0.03{ }^{\circ} \mathrm{C} / \mathrm{s}$ (Protocol by Sigma-Aldrich (Sigma-Aldrich 2020)).

\section{Strain generation and molecular methods}

\section{Strain generation}

Strains used in this study are depicted in Table 2. All strains had the $n k u A \Delta$ background to reduce non-homologous end joining and facilitate homologous recombination events (Nayak et al. 2006). Strains were transformed by using protoplast transformation (Tilburn et al. 1983). All transformations were conducted with circular plasmids. For generation of strain VPR4, strain A1153 was transformed with $p$ VPR4. After single spore isolation, the in situ integration (i.e. $\arg B$ ) and presence of all relevant features of $p$ VPR 4 was verified by PCR. Primer pairs that were used for the verification of strain VPR4 and the results can be obtained from Supplementary Table S1 and Supplementary Fig. S1, respectively. A correct transformant was then transformed with plasmid $p$ sgRNA containing a sgRNA. In case of multiple sgRNA-carrying strains (i.e. VPR4-mAll, VPR4-m1\&m2, VPR4-m2\&m3), plasmids $p$ sgRNA-m 1 to $\mathrm{m} 4$ were transformed simultaneously and the uptake of different combinations was verified by PCR. In case of strain VPR4-A1 and A2, either $p$ sgRNA-A1 or $p$ sgRNA-A2 was transformed into VPR4. For sgRNAcarrying strains, the presence of the specific sgRNA was verified by PCR as well. Information about primer pairs and results of the PCRs can be obtained from Supplementary Table S1 and Supplementary Fig. S2, respectively. DNA was extracted according to Cenis (1992) with following deviation. Prior to extraction, the fungus was grown on solid Aspergillus minimal media (AMM; Barratt et al. (1965)) and subsequently a thin layer of mycelia was transferred into a Lysing matrix A tube (MP Biomedicals; Irvine, CA; Art. No.: SKU 116910100). The material was then homogenised in a FastPrep-24TM (MP Biomedicals, Art. No.: SKU 116004500 ) at $6 \mathrm{~m}^{*} \mathrm{~s}^{-1}$ for $20 \mathrm{~s}$ in Cenis lysis buffer. DNA was used for fragment amplification for YRC $(Q 5 \AA$ polymerase (New England Biolabs; Art. No.: M0491L) and for diagnostic PCR reactions (GoTaq ${ }^{\circledR}$ Green Master Mix (Promega; Madison, WI, USA; Art. No.:M7845). PCR was performed according to the respective manufacturer's instruction. 
Table 2 Aspergillus nidulans strains used during this study. All strains that are used for activation experiments are descendants of strain FGSC A1153. The suffixes T1/T2/T3 in column "Strain" refer to the different independent transformants per construct. In parenthesis are the strain numbers of our in-house collection

\begin{tabular}{|c|c|c|c|c|}
\hline Strain & Genotype & $\begin{array}{l}\text { Parent } \\
\text { strain }\end{array}$ & $\begin{array}{l}\text { Transformed } \\
\text { plasmid }\end{array}$ & Reference \\
\hline WIM 126 (\#3) & $y A 2, p a b a A 1, v e A^{+}$ & - & - & $\begin{array}{l}\text { Mooney and Yager } \\
\text { (1990) }\end{array}$ \\
\hline $\begin{array}{l}\text { FGSC A1153 } \\
\quad(\# 634)\end{array}$ & $\begin{array}{l}\text { yA1 pabaA1 pyroA4 } \arg B 2 \\
\quad \text { nkuA::bar }\end{array}$ & - & - & $\begin{array}{l}\text { McCluskey et al. } \\
\text { (2010) }\end{array}$ \\
\hline VPR4 (\#833) & $\begin{array}{l}\text { yA1 pabaA1 pyroA4 } \\
\quad \text { nkuA::bar }\end{array}$ & A1153 & $p$ VPR4 & This study \\
\hline VPR4-m1 (\#834) & yAl pabaAl nkuA::bar & VPR4 & $p$ sgRNA-m1 & This study \\
\hline VPR4-m2 (\#835) & yAl pabaAl nkuA::bar & VPR4 & $p$ sgRNA-m2 & This study \\
\hline VPR4-m3 (\#836) & yAl pabaAl nkuA::bar & VPR4 & $p$ sgRNA-m3 & This study \\
\hline $\begin{array}{l}\text { VPR4-m4-T1 } \\
\text { (\#837) }\end{array}$ & yAl pabaAl nkuA::bar & VPR4 & $p$ sgRNA-m4 & This study \\
\hline $\begin{array}{l}\text { VPR4-m4-T2 } \\
\quad(\# 838)\end{array}$ & yAl pabaAl nkuA::bar & VPR4 & $p$ sgRNA-m4 & This study \\
\hline $\begin{array}{l}\text { VPR4-m1\&2 } \\
\quad(\# 839)\end{array}$ & yAl pabaAl nkuA::bar & VPR4 & $\begin{array}{l}p \operatorname{sgRNA}-\mathrm{m} 1 \\
p \text { sgRNA-m2 }\end{array}$ & This study \\
\hline $\begin{array}{l}\text { VPR4-m2\&3 } \\
\quad(\# 840)\end{array}$ & yAl pabaAl nkuA::bar & VPR4 & $\begin{array}{l}p \text { sgRNA-m2 } \\
p \text { sgRNA-m3 }\end{array}$ & This study \\
\hline $\begin{array}{l}\text { VPR4-mAll-T1 } \\
\quad(\# 841)\end{array}$ & yAl pabaAl nkuA::bar & VPR4 & $\begin{array}{l}p \text { sgRNA-m1 } \\
p \text { sgRNA-m2 } \\
p \text { sgRNA-m3 } \\
p \text { sgRNA-m4 }\end{array}$ & This study \\
\hline $\begin{array}{l}\text { VPR4-mAll-T2 } \\
\quad(\# 842)\end{array}$ & yAl pabaAl nkuA::bar & VPR4 & $\begin{array}{l}p \text { sgRNA-m1 } \\
p \text { sgRNA-m2 } \\
p \text { sgRNA-m3 } \\
p \text { sgRNA-m4 }\end{array}$ & This study \\
\hline $\begin{array}{l}\text { VPR4-A1-T1 } \\
\quad(\# 843)\end{array}$ & yAl pabaAl nkuA::bar & VPR4 & $p$ sgRNA-A1 & This study \\
\hline $\begin{array}{l}\text { VPR4-A1-T2 } \\
\quad(\# 844)\end{array}$ & yAl pabaAl nkuA::bar & VPR4 & psgRNA-A1 & This study \\
\hline $\begin{array}{l}\text { VPR4-A1-T3 } \\
\quad(\# 845)\end{array}$ & yA1 pabaAl nkuA::bar & VPR4 & $p$ sgRNA-A1 & This study \\
\hline $\begin{array}{l}\text { VPR4-A2-T1 } \\
\quad(\# 846)\end{array}$ & yAl pabaAl nkuA::bar & VPR4 & $p$ sgRNA-A2 & This study \\
\hline $\begin{array}{l}\text { VPR4-A2-T2 } \\
(\# 847)\end{array}$ & yAl pabaAl nkuA::bar & VPR4 & $p$ sgRNA-A2 & This study \\
\hline $\begin{array}{l}\text { VPR4-A2-T3 } \\
\quad(\# 848)\end{array}$ & yA1 pabaA1 nkuA::bar & VPR4 & $p$ sgRNA-A2 & This study \\
\hline
\end{tabular}

Annealing temperature was set to $58^{\circ} \mathrm{C}$ for $\mathrm{Q} 5 \AA$ amplifications and to $60{ }^{\circ} \mathrm{C}$ for GoTaq ${ }^{\circledR}$ amplifications. For RNA isolation, freeze-dried mycelium was ground to a fine powder using mortar and pestle under liquid nitrogen and RNA was extracted with TRIzol ${ }^{\mathrm{TM}}$ Reagent (Invitrogen; Carlsbad, CA, USA; Art. No.: 15596026) according to the manual. RNA content was measured using a NanoDrop ${ }^{\mathrm{TM}}$ spectrophotometer (Thermo Fisher Scientific ${ }^{\mathrm{TM}}$; Art. No.: ND-2000C). For cDNA synthesis, $2 \mu \mathrm{g}$ total RNA was treated with DNaseI (Thermo Fisher Scientific ${ }^{\mathrm{TM}}$; Art. No.: EN0521). Complete removal of any residual DNA was then verified by PCR with the primer pair for the gene actA (AN6542), actA-control (Supplementary Table S1). Next, $1 \mu \mathrm{g}$ of DNA-free sample was taken for cDNA synthesis (Bio-Rad; Hercules, CA, USA; iScript $^{\mathrm{TM}}$ cDNA Synthesis Kit, Art. No.: 1708891).
Successful cDNA synthesis was again verified using the primer pair actA-control (Supplementary Table S1).

\section{Reverse transcriptase quantitative polymerase chain reaction (RT-qPCR) analysis}

The cDNA was diluted $1 / 5$ with $\mathrm{dH}_{2} \mathrm{O}$ and $2.5 \mu \mathrm{L}$ was used for qPCR analysis $(10 \mu \mathrm{L}$ total volume; Bio-Rad, iTaq Universal SYBR Green Supermix; Art. No.: 172-5124) in a Bio-Rad CFX384 C1000 Touch Thermal cycler. The qPCRs were done in technical duplicates. Only primer pairs with an efficiency between 90 and $110 \%$ were considered for qPCR analysis. The genes of interest were compared with the housekeeping genes actA (AN6542) and benA (AN1182) and the relative fold change in expression was calculated according to 
the $2^{-\Delta \Delta \mathrm{Ct}}$ method (Livak and Schmittgen 2001). The qPCR program was run as follows: $95^{\circ} \mathrm{C}(3 \mathrm{~min})-40$ repetitions of $\left(95{ }^{\circ} \mathrm{C}(10 \mathrm{~s})-60{ }^{\circ} \mathrm{C}\right.$ or $\left.64{ }^{\circ} \mathrm{C}(10 \mathrm{~s})-72{ }^{\circ} \mathrm{C}(30 \mathrm{~s})\right)-95{ }^{\circ} \mathrm{C}$ (10 s)-melting curve $\left(65^{\circ} \mathrm{C}-95^{\circ} \mathrm{C}\right.$ at $0.5{ }^{\circ} \mathrm{C}$ intervals and 5 -s hold at each interval). All qPCR primer pairs were run at an annealing temperature of $60{ }^{\circ} \mathrm{C}$ apart from primers for $m d p G$ which were run at $64{ }^{\circ} \mathrm{C}$. A complete list of qPCR primers can be found in Supplementary Table S1.

\section{Nucleosome mapping}

A. nidulans (strain WIM 126 (Mooney and Yager 1990)) was grown in shaking flasks for 15 or $48 \mathrm{~h}$ in AMM supplemented with $1 \%$ glucose, $100 \mathrm{mM}$ sodium nitrate and paraaminobenzoic acid (paba; Sigma-Aldrich, Steinheim am Albuch, Germany; Fluka; Art. No.: 06930). Before harvest, mycelia were fixed with $1 \%$ formaldehyde (Roth; Art. No.: 4979) for $15 \mathrm{~min}$ and fixation was stopped with $1 \mathrm{M}$ glycine (Carl Roth; Karlsruhe, Germany; Art. No.: 3790). Mycelia were filtered and shock frozen in liquid nitrogen prior to grinding using a mortar and pestle.

To fragment the DNA, mycelia were suspended in $2 \mathrm{~mL}$ MNase digestion buffer (50 mM HEPES pH 7.5 (Sigma; Art. No.: 3375), $50 \mathrm{mM} \mathrm{NaCl}$ (Carl Roth; Art. No.: 3957), $5 \mathrm{mM} \mathrm{MgCl} 2$ (Carl Roth; Art. No.: KK36.1), $1 \mathrm{mM} \mathrm{CaCl}_{2}$ (Carl Roth; Art. No.: A119.1), 1× proteinase inhibitor mix (Sigma; Art. No.: P8215) and $1 \mathrm{mM}$ phenylmethylsulfonyl fluoride (PMSF, Sigma; Art. No.: 6367) and $300 \mu \mathrm{L}$ aliquots of suspension were treated with $0.4 \mathrm{U}$ micrococcal nuclease (MNase, Sigma; Art. No.: N3755) at $37{ }^{\circ} \mathrm{C}$ for $6 \mathrm{~min}$. The MNase reaction was stopped by adding $300 \mu \mathrm{L}$ stop buffer $2(50 \mathrm{mM}$ HEPES pH 7.5, $255 \mathrm{mM} \mathrm{NaCl}, 40 \mathrm{mM}$ EDTA (Carl Roth; Art. No.: 8040), $2 \%$ triton X-100 (Sigma; Art. No.: 8787 ) and $0.2 \%$ sodium deoxycholate (Sigma; Art. No.: D6750). Fixation was reversed by incubation for 15 min at $65{ }^{\circ} \mathrm{C}$, the supernatant was purified using a PCR purification kit (Qiagen; Hilden, Germany; Art. No.: 28181) and samples were electrophoresed on a $1.5 \%$ agarose gel to check the MNase digestion. Sequencing library preparation and sequencing was performed at Vienna BioCenter Core Facilities. Illumina libraries were prepared using Nextera XT DNA Library Preparation Kit and paired end 50 bp sequencing was done on an Illumina HiSeq 2000 system. Obtained fastq files were mapped on A. nidulans WIM 126 genome assembly using BWA (version 0.7.17) and coverage per base pair was calculated using samtools (version 1.9) and bedtools (version 2.28.0) to receive a representation of the genome-wide nucleosome occupancy. The datasets were uploaded to the NCBI Sequence Read Archive (SRA) with the submission numbers SRR12336645 (15 h) and SRR12336644 (48 h).

\section{Guide RNA design}

The region of interest was analysed for the occurrence of the protospacer adjacent motifs (PAMs; i.e. NGG) and possible protospacer sequences (i.e. target-specific sequence of sgRNA) were subjected to a full genome blast against the genome of A. nidulans to select the protospacers that are closest to the anticipated locus with least possible off-targets. The borders of nucleosome-free regions were designated as the region between a 75 base pair offset from the adjacent dyad axis (i.e. peak maximum) (see Fig. 4 and Fig. 6). In case of the activation of $m d p E$, sgRNA sequences upstream as well as downstream of the nucleosome-free region were chosen additionally. Two sgRNAs were positioned close to the predicted transcriptional start site (TSS) of $m d p E$. Sequences of sgRNAs can be retrieved from Supplementary Table S2. The positioning of the sgRNAs within the genome is shown in Fig. 4 and Fig. 6.

\section{Media and growth conditions for activation experiments}

During activation experiments, controls and activation strains were all grown and treated under identical conditions. $4 * 10^{6}$ conidia per $\mathrm{mL}$ AMM media were inoculated in $60 \mathrm{~mL}$ AMM liquid media and $10 \mathrm{mM}$ nitrate as nitrogen source. The cells were grown for $40 \mathrm{~h}$ at $37^{\circ} \mathrm{C}$ and $180 \mathrm{rpm}$ on orbital shaker platforms before adding the inducer to all flasks (i.e. samples as well as controls (=VPR4)). The inducer mix contained $75 \mathrm{nM}$ diethylstilbestrol (DES; Sigma-Aldrich, Art. No.: 4628) in ethanol absolute (glass flask: Sigma; EMPARTA ${ }^{\circledR}$ ACS: Art. No.: 1070172511) (final inducer concentration: 33 $\mathrm{pM}$ DES). After induction, cultures were incubated for further $8 \mathrm{~h}$. Subsequently $1 \mathrm{~mL}$ of supernatant was taken for SM analysis as described in section "SM analysis". Mycelia were harvested by filtering through Miracloth fabric (Millipore; Burlington, MA, USA; Art. No.: 475855-1R), washed in $\mathrm{dH}_{2} \mathrm{O}$, frozen in liquid nitrogen and freeze-dried for dry mass determination and transcript analysis.

\section{Phenotyping}

The growth phenotype was determined on solid complete media (CM by DR. C. F. Robert (Barratt et al. 1965)), AMM and AMM supplemented with different concentrations of DES (Sigma, Art. No.: 4628) between 0.033 and 50 nM. Plates were inoculated with $10 \mu \mathrm{L}$ of a 100 spores $/ \mu \mathrm{L}$ spore suspension and incubated for 4 days at $37^{\circ} \mathrm{C}$ in the dark. After 4 days, radial growth was measured and a picture was taken. Each growth test was done in triplicates. Additionally, the dry mass accumulation and production of SMs (i.e. penicillin G, sterigmatocystin, austinol, dehydroaustinol, emericellamide A) were compared under the same conditions as during 
activation experiments (section "Media and growth conditions for activation experiments") with the exception of comparing DES-induced and not induced VPR4 strains.

\section{SM analysis}

One millilitre of supernatant of $A$. nidulans liquid culture was analysed. The samples were run on a QTrap 5500 LC-MS/MS System (Applied Biosystems, Foster City, CA, USA) equipped with a TurboIonSpray electrospray ionisation (ESI) source and a 1290 Series HPLC System (Agilent, Waldbronn, Germany). Chromatographic separation was done at $25^{\circ} \mathrm{C}$ using a Gemini $\mathrm{C} 18150 \times 4.6 \mathrm{~mm}$ i.d., $5 \mu \mathrm{m}$ particle size, equipped with a $\mathrm{C} 183 \times 4 \mathrm{~mm}$ i.d. security guard cartridge (Phenomenex, Torrance, CA, USA). The chromatographic method and chromatographic and mass spectrometric parameters are described elsewhere (Sulyok et al. 2020). The concentration of each metabolite was then normalised to the generated dry mass during cultivation.

\section{Results}

\section{Systems development and experimental design}

An overview of the system and the workflow are shown in Fig. 1 (plasmids) and Fig. 2 (workflow). To develop the system, we consecutively transformed A. nidulans FGSC A1153 with two constructs. First, plasmid VPR4 is constitutively expressing $h E R$ and an inducible (mediated by activated hER) VPR-dCas 9 . The expression of $V P R-d C a s 9$ can be induced by the addition of estrogens (i.e. DES) which leads to the activation of hER, its subsequent dimerisation, binding to estrogen response elements (EREs; i.e. promoter region of $V P R-d \operatorname{Cas} 9$ ) and activation of respective genes (Pachlinger et al. 2005). A verified transformant carrying $p$ VPR4 was then used as the recipient strain for the second plasmid which carries the constitutively expressed sgRNA cassette (descendants of $p \operatorname{sgRNA}$ ). The sgRNA is flanked by a hammerhead ribozyme and a HDV ribozyme to facilitate the proper processing and release of functional sgRNAs (Nødvig et al. 2015). During activation experiments, strain VPR4 was used as control strain to rule out artefacts that originate from components of plasmid VPR4 (i.e. VPR-dCas $9, h E R$ ) or the inducer. An overview on the whole experimental workflow is shown in Fig. 2.

To improve correct positioning and "landing" of sgRNAloaded VPR-dCas9 at the selected target region, we considered two points. First, the synthetic activator should be located at a suitable distance from the expected general transcriptional machinery to ensure efficient contacts between the activator, Mediator complex and the RNA-Polymerase II complex. We therefore positioned VPR-dCas9 at different distances from the predicted transcriptional start site of the target gene. Secondly, we hypothesised that the sgRNA target sequences should not be buried in densely packed nucleosomes but optimally lie in nucleosome-free regions. We therefore performed genome-wide nucleosome accessibility assays using micrococcal nuclease digests followed by whole genome sequencing (MNase-seq). Two nucleosome positioning maps were created in the wild-type strain WIM 126 grown at two different physiological conditions on defined AMM, i.e. conditions of active growth (i.e. primary metabolism; $15 \mathrm{~h}$ shake cultures) and in stationary phase (i.e. secondary metabolism; $48 \mathrm{~h}$ shake cultures). Transformants with verified correct molecular integration events of $p$ VPR4 (i.e. strain VPR4) were analysed for SM production under non-induced and DESinduced (i.e. activating) conditions (section: "Media and growth conditions for activation experiments") to exclude that the addition of estrogens already results in elevated levels of SMs without any sgRNA-directed targeting of VPR-dCas9 (Supplementary Fig. S4). Finally, during activation experiments, sgRNA-carrying strains and control strain (i.e. VPR4) were treated as described in section "Media and growth conditions for activation experiments". Target gene transcription was measured by reverse transcriptase quantitative polymerase chain reaction (RT-qPCR) and the mean fold change in expression was determined by comparing sgRNAcarrying strains to control strain (i.e. VPR4). Plasmids and strains that were used or created during this study are listed in Table 1 and Table 2.

\section{hER-containing strains show slight stress phenotypes in the presence of DES}

As the activation system is based the estrogen-inducible $V P R$ $d \operatorname{Cas} 9$, we first tested if the combination of hER and estrogen already led to a background activity of the SM clusters which we planned to activate at a later step. For this, we first controlled the growth phenotypes of $h E R$-containing strains and found that the activated estrogen receptor has a significant impact on growth of the strains when elevated amounts of DES are applied. The phenotype of the strain VPR4 and strains additionally carrying a guide RNA was identical. Strains that do not carry $h E R$ (i.e. FGSC A1153) are not affected by elevated DES levels (Supplementary Fig. S3). To check if $h E R$ is the cause for this phenotype, two other strains that only carry the $h E R$ under a constitutive promoter were also grown under same conditions (data not shown). This experiment verified that the activated estrogen receptor causes this phenotype which is in accordance with our previous observations (Pachlinger et al. 2005). The maximal inducer concentration that was tolerated by the actual strains without displaying any morphological phenotype was above $33 \mathrm{pM}$ DES. One hundred pM DES already showed a clear reduction in colony diameter. Consequently, for subsequent activation 


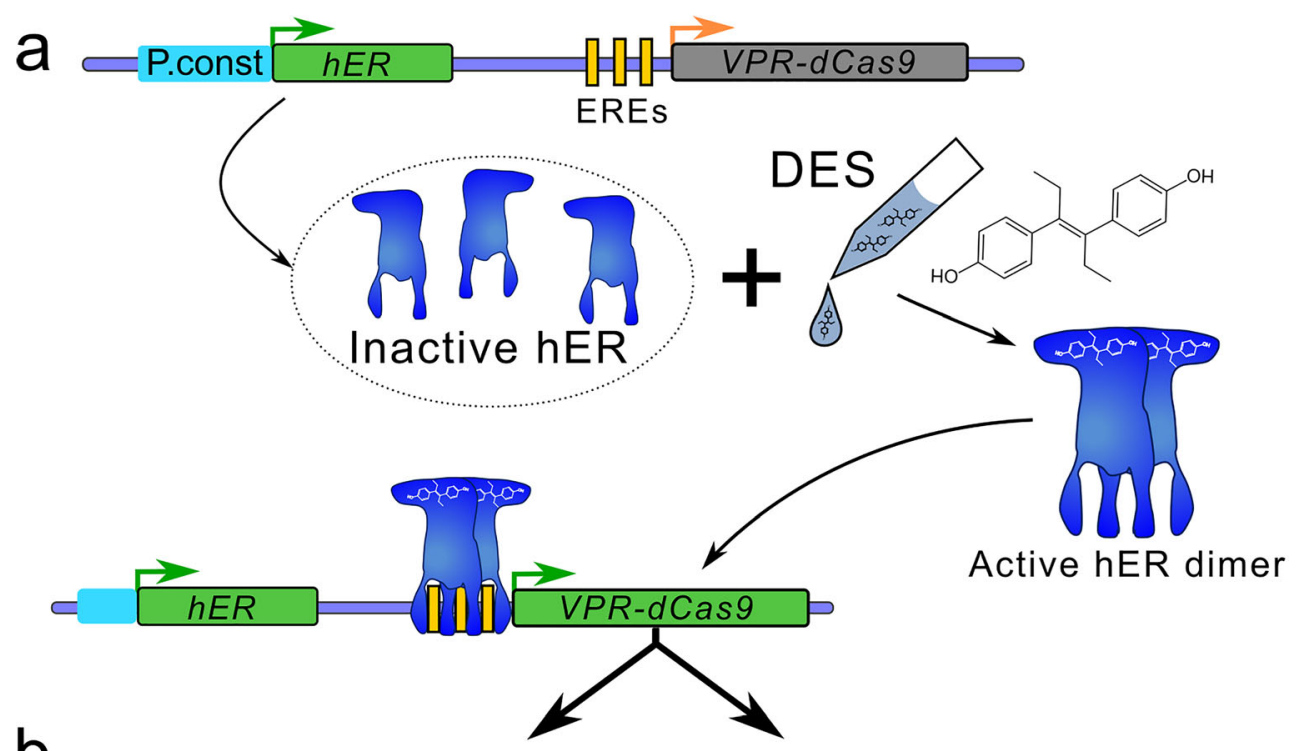

b

\section{Control strain}

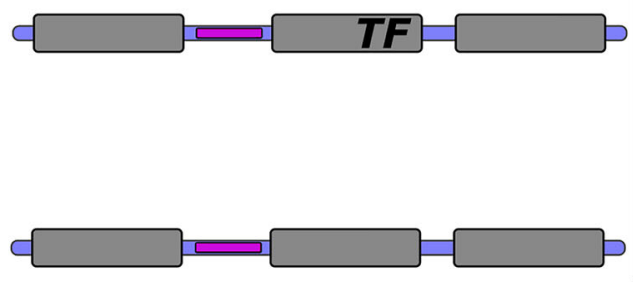

Fig. 2 VPR-dCas9 activation and experimental design. Green or grey rectangulars represent expressed or not expressed genes respectively. Green arrows indicate active promoters while orange arrows represent promoters poised for activation. a All strains carry plasmid VPR4 (control as well as activation strains). pVPR 4 contains the constitutively expressed (P.const; cyan) human estrogen receptor gene (hER) which is inactive in absence of the inducer. Upon induction with DES, hER is activated and able to bind to estrogen response elements (EREs; vertical yellow bars) which are present in the engineered VPR-dCas9 gene promoter. Upon binding, hER facilitates transcription of the gene that codes for VPR-dCas9. b In the control strain (only pVPR4), sgRNAs are not expressed and thus VPR-dCas9 is present in the cell but not targeted to the designated region of interest (horizontal violet bars). The activation

\section{Activation strain}

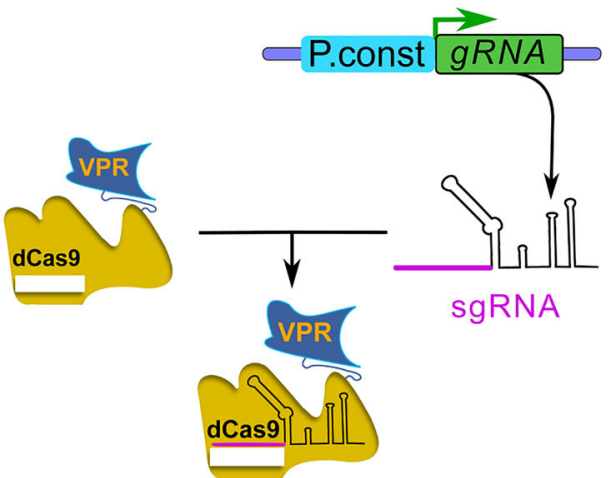

Guided activator

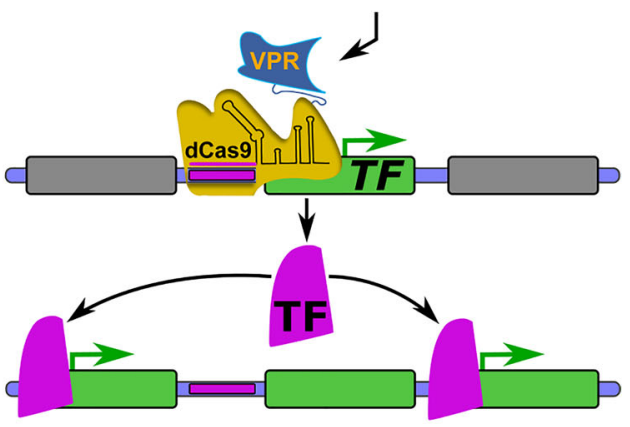

strains (pVPR4 and one or more psgRNA with functional sgRNA cassette) constitutively express $\operatorname{sgRNA}(\mathrm{s})$ (target sequence in violet) which guide VPR-dCas9 to the region of interest (horizontal violet bars) and facilitate transcription of the targeted gene (i.e. TF). Hence, the activation strain should experience an elevated expression of the targeted gene compared with the control strain, which can only be attributed to the presence of the sgRNA. In one application, the targeted gene could be a transcription factor gene (TF) of a silent BGC and forced expression of this TF gene could subsequently lead to the upregulation of the whole cluster as shown in the figure. In another scenario, several sgRNAs could be targeted to many genes within a predicted cluster and the cognate metabolite(s) could be identified subsequently 
experiments, 33 pM DES was chosen as final inducer concentration which has already been documented to trigger strong activation (Pachlinger et al. 2005). Furthermore, this concentration had no effect on dry mass accumulation. The effect on SM background levels was not significant (Supplementary Fig. S4). We concluded that the system is suitable to be applied for the forced activation of the chosen SM cluster genes.

\section{Activation of the silent monodictyphenone gene cluster}

For a proof-of-concept, we chose the monodictyphenone ( $m d p$ ) cluster of $A$. nidulans which was shown to be silent under standard laboratory conditions in a wild-type strain because the cluster is subject to negative chromatin-level control by the COMPASS (Bok et al. 2009) and the H3K4 demethylase KdmB (Gacek-Matthews et al. 2016). The $m d p$ cluster comprises at least 10 genes. Among them are $m d p E$, which encodes a transcription factor, and $m d p G$, the backbone gene which encodes a non-reducing PKS (NR-PKS). This BGC was analysed in more detail by Chiang and colleagues who showed that overexpression of $m d p E$ is necessary and sufficient to activate the backbone gene $m d p G$ and all other cluster genes to eventually synthesise the final product monodictyphenone (Chiang et al. 2010). We therefore guided VPR-dCas9 to the $m d p E$ gene promoter. An overview on the cluster, its expression profile under primary and secondary metabolic conditions and corresponding nucleosome positioning maps are shown in Fig. 3.

To test the effect of different VPR-dCas9 positions in relation to the predicted NFRs, we designed 4 different sgRNAs according to the high-resolution map of the $m d p E$ upstream region including the $5^{\prime}$ untranslated region (UTR) and nucleosome positions as shown in Fig. 4a. The sgRNAs $\mathrm{m} 1$ and $\mathrm{m} 2$ were positioned close to the predicted TSS of $m d p E ; \mathrm{m} 3$ was positioned directly inside the first obvious upstream NFR which encompasses roughly $50 \mathrm{bps}$ and lies around $300 \mathrm{bps}$ upstream of the TSS. Finally, $\mathrm{m} 4$ was selected to bind even further upstream from the TSS, i.e. roughly $600 \mathrm{bps}$ upstream (Fig. 4a). There would be another NFR at $\sim 700-800$ bps upstream but RNA-seq data suggest that this could very well belong to the downstream UTR of the gene AN0149 and was therefore not considered for sgRNA design. The expression analyses of $m d p E$ in strains having VPR-dCas9 positioned at these different places either alone or in combination with other sgRNAs are shown in Fig. 4b. Interestingly, in this promoter, positioning of VPR-dCas9 by any single sgRNA is obviously not sufficient for activation of $m d p E$ because all measured transcript levels were in the range of the control strain. A clear activation potential was mediated only by sgRNA combinations of either two or all four guide RNAs. The combination of $\mathrm{m} 1+\mathrm{m} 2(\mathrm{~m} 1 \& 2)$ already showed a clear activation of $m d p E$ in the range of 7-fold higher transcript levels compared with the background found in the control strain grown under the same conditions. When $\mathrm{m} 2$ was

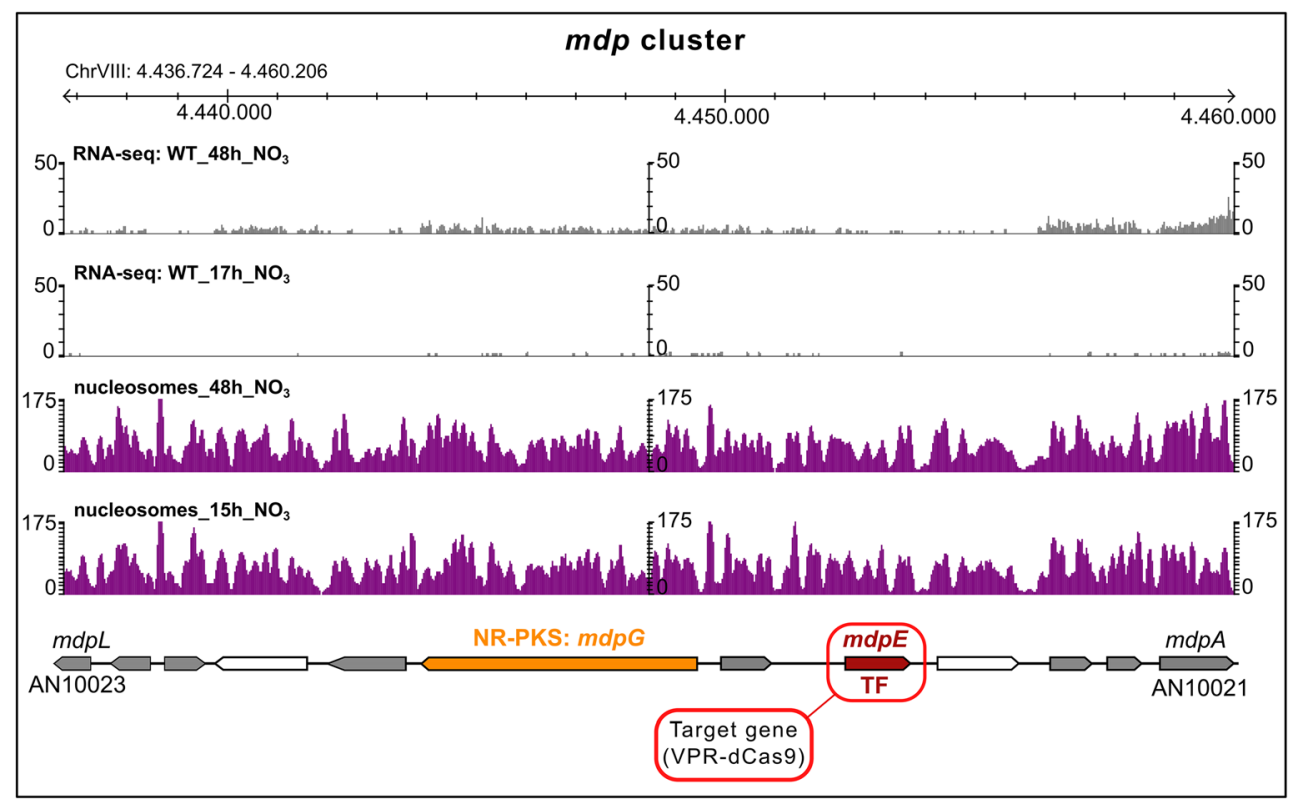

Fig. 3 Overview of the monodictyphenone cluster of A. nidulans. The section spans the whole cluster. Apart from gene annotations (arrows), nucleosome positioning as well as the mRNA profile (Gacek-Matthews et al. 2016) at nutrient-rich (15/17 h) and nutrient-depleted (48 h) conditions are depicted in purple and grey histograms respectively. White arrows are genes that are not necessary for the synthesis of the BGC products. Grey, orange and ruby arrows are genes involved in the monodictyphenone biosynthesis. The orange arrow is the backbone gene of the cluster which encodes for the non-reduced polyketide synthase MdpG. The ruby arrow is the gene that encodes for the pathwayspecific transcription factor MdpE which is the target for the activation by VPR-dCas9 
Fig. 4 Targeted activation of the transcription factor gene $\mathrm{mdpE}$ via VPR-dCas9 and MdpEmediated activation of the backbone gene mdpG. a Promoter region of the target gene mdpE together with RNA-sequencing data (grey histograms; GacekMatthews et al. (2016)) and nucleosome positioning maps (purple histograms) under nutrientrich $(15 / 17 \mathrm{~h})$ and nutrientdepleted ( $48 \mathrm{~h}$ ) conditions. The nucleosome-free region (NFR) is shown in grey white pattern which is delimited by the nucleosomal borders (set to an offset of 75 base pairs proximal to the dyad axis of the neighbouring nucleosomes). The dyad axes are shown in vertical blue dashed lines and were set at the peak of the nucleosome histogram. Positions of sgRNAs are depicted in red ( $\mathrm{ml}-$ m4). b Expression of the gene $\mathrm{mdpE}$ in the controls (only pVPR4) and strains that additionally carry one or more sgRNAs $(\mathrm{m} 1|\mathrm{~m} 2| \mathrm{m} 3|\mathrm{~m} 4| \mathrm{m} 1 \& 2 \mid$ $\mathrm{m} 2 \& 3 \mid \mathrm{mAll})$ that target the promoter region of the gene $m d p E$. $\mathbf{c}$ Expression of the backbone gene $m d p G$ in the same samples as shown in $\mathbf{b}$ which is caused by the activation of $m d p E$. Cultures were done in triplicates, and qPCR was done in technical duplicates. A Student's $t$ test was used to verify the significance of the activation over the controls (i.e. VPR4) $(* p<0.05 ; * * p<0.01)$

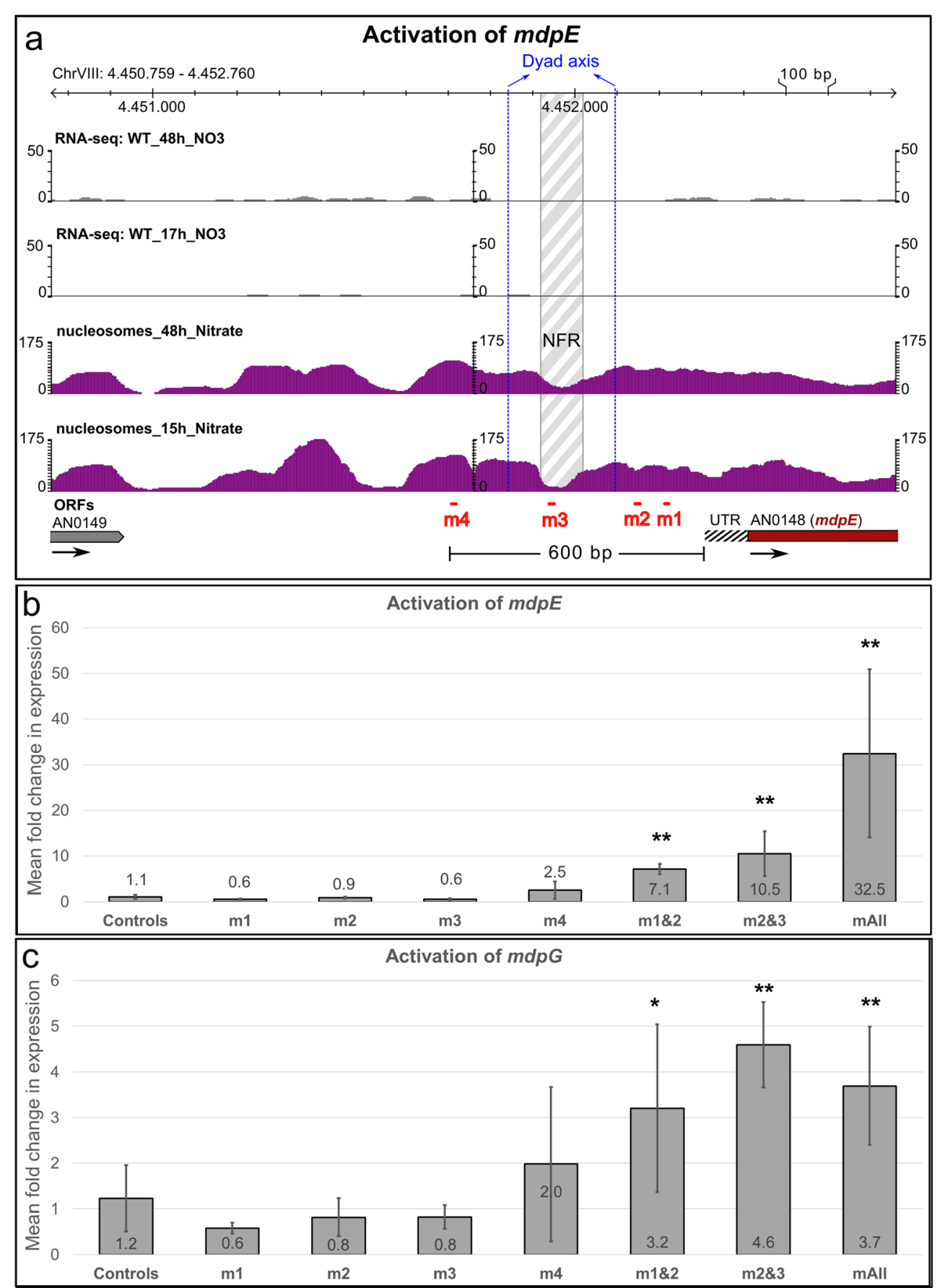

combined with $\mathrm{m} 3(\mathrm{~m} 2 \& 3)$ that binds to the NFR, the activation was rising to 10 -fold above background levels. The highest potential was found when all four chosen sgRNAs $\mathrm{m} 1$ to $\mathrm{m} 4$ (mAll) were expressed in one strain together with VPR-dCas9. In this case, $m d p E$ expression was activated roughly 30 -fold over the background of the control strain. These results indicate that both spatial positioning and the amount of VPR-dCas9 present at the promoter define the functionality of this fusion protein as synthetic activator.

To see if the $m d p E$ expression levels are sufficiently high to yield a functional amount of the MdpE transcription factor, we tested the same samples also for expression of $m d p G$. RT-qPCR analysis shown in Fig. 4c documents that the forced expression of $m d p E$ results in upregulation of its target gene $m d p G$. We detected a similar expression pattern of both genes. Consistent with the function of $\mathrm{MdpE}$ as cluster-specific TF, activation of $m d p G$ was only achieved in samples where $m d p E$ was expressed successfully, i.e. when at least two different sgRNAs were expressed simultaneously in the strain. Even if the expression levels of the two genes show a similar trend, it should be noted, however, that the 
amplitude of $m d p G$ activation was much lower than for the "direct" VPR-dCas9 target $m d p E$ (note the scale in yaxes of Fig. 4b and Fig. 4c).

\section{Activation of a silent BGC of unknown function}

As second example for proof-of-concept, we chose a predicted gene cluster for which no experimental evidence is available so far and no cognate metabolite is known. Genes at this target location are predicted to be part of the BGC-AN8504 (Inglis et al. 2013) which is a putative gliP-like NRPS (Cerqueira et al. 2014). A cluster prediction program delineates the putative BGC (prediction tool antiSMASH (Medema et al. 2011)) comprising presumably 16 genes from AN8495 to AN8508 and containing the putative NRPS-encoding gene AN8504 as well as a putative TF encoded by AN8506 (Fig. 5). The nucleosome maps of this region show that the predicted BGC has a number of pronounced nucleosome-free regions which made it suitable for our tests.

We targeted the promoter of the TF gene AN8506 which seems to share a very small 305 bp-control region with the divergently transcribed gene AN8507 encoding a predicted transmembrane transport protein (Cerqueira et al. 2014). The control region contains a clearly formed NFR that would perfectly serve as entry point for sgRNAs to position our activator. Interestingly, despite sharing a common promoter, the transcriptional levels differed between both genes under previously tested conditions (Schinko et al., 2010, GacekMatthews et al. 2016; see Fig. 5). While AN8506 (TF) was weakly transcribed in both $17 \mathrm{~h}$ and $48 \mathrm{~h}$ cultures (nutrientlimited conditions; see RNA-seq data in Fig. 5), the transmembrane protein AN8507 was completely silent. This bidirectional promoter region therefore served a suitable site to test how the positioning of VPR-dCas9 in relation to the TSS of the divergently transcribed genes influences their transcription pattern. The expression profiles and nucleosome positioning maps of all genes putatively forming a BGC are shown in Fig. 5.

AN8506 and AN8507 are controlled by a bidirectional promoter of only $305 \mathrm{bps}$ in length that clearly contains a NFR roughly in the middle (Fig. 6a). We designed two different sgRNAs for targeting VPR-dCas9 inside the NFR. The idea was to test how the position of the activator in relation to the gene would influence its activation potential. sgRNA A1 was designed to bind close to AN8506 and A2 should bind close to AN8507. The high-resolution nucleosome positioning map in Fig. 6a shows that the +1 nucleosome of the moderately expressed gene AN8506 is very well positioned at both time points while this is not the case for AN8507. In the activation experiment shown in Fig. 6b, we found that AN8506 is moderately activated by both sgRNAs in a similar range, i.e. roughly 6-fold by A 1 and 3.5 -fold by A2 suggesting that A1 positions VPR-dCas9 slightly better in relation to the general transcriptional machinery responsible for AN8506

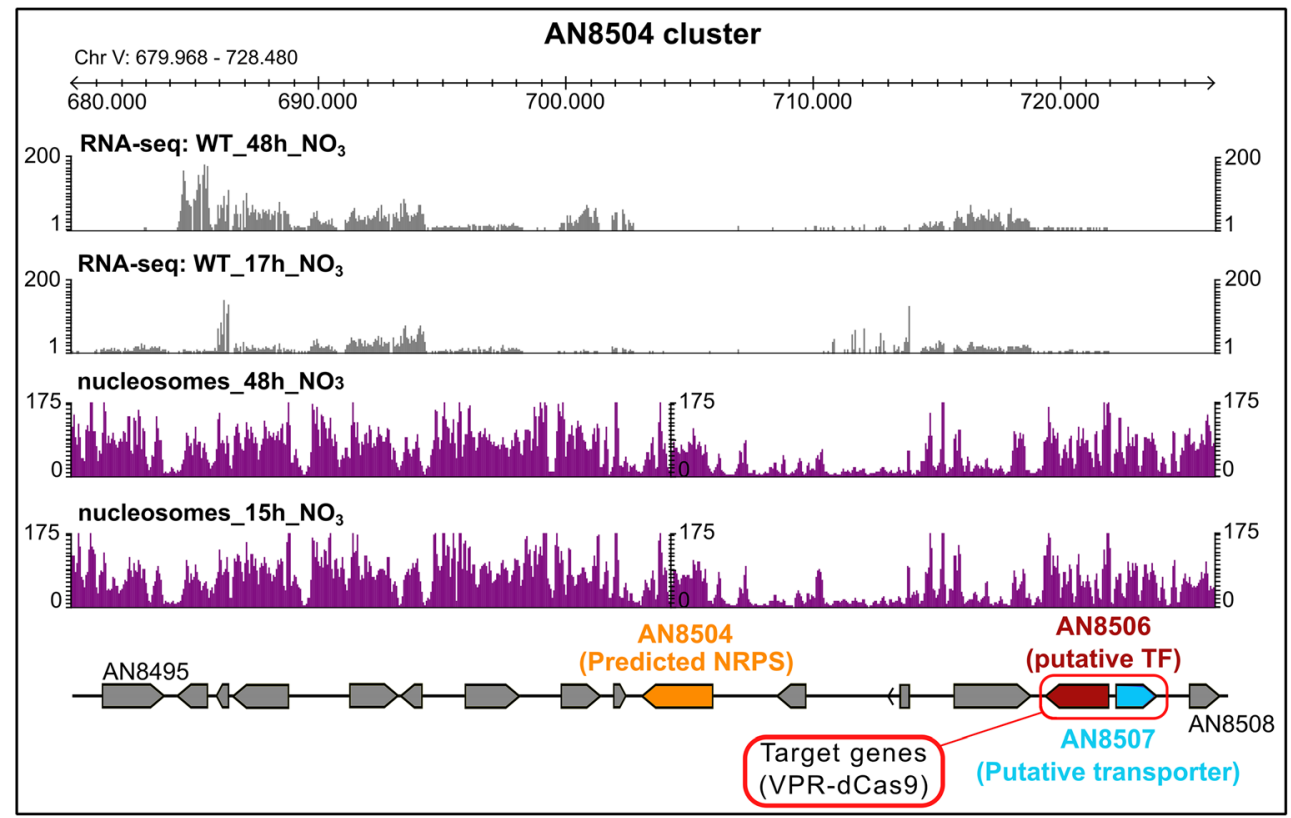

Fig. 5 Overview of the predicted cluster AN8504 of A. nidulans. The cluster (as predicted by antiSMASH) begins at gene AN8495 and ends at AN8508. Nucleosome positioning as well as the mRNA profile (GacekMatthews et al. 2016) at nutrient-rich $(15 / 17 \mathrm{~h})$ and nutrient-depleted $(48 \mathrm{~h})$ conditions is depicted in purple and grey histograms respectively. The backbone gene (AN8504; orange arrow) shows no transcription at either condition. Two sgRNAs were designed that target VPR-dCas9 to the bidirectional promoter that regulates the genes AN8506 and AN8507 (red frame). AN8506 (ruby arrow) is the putative transcription factor and AN8507 (cyan arrow) is the putative membrane protein. AN8506 shows a low basal transcription level (comparable with 0.32 times of the expression level of the housekeeping gene benA) while AN8507 shows no reads at either condition 

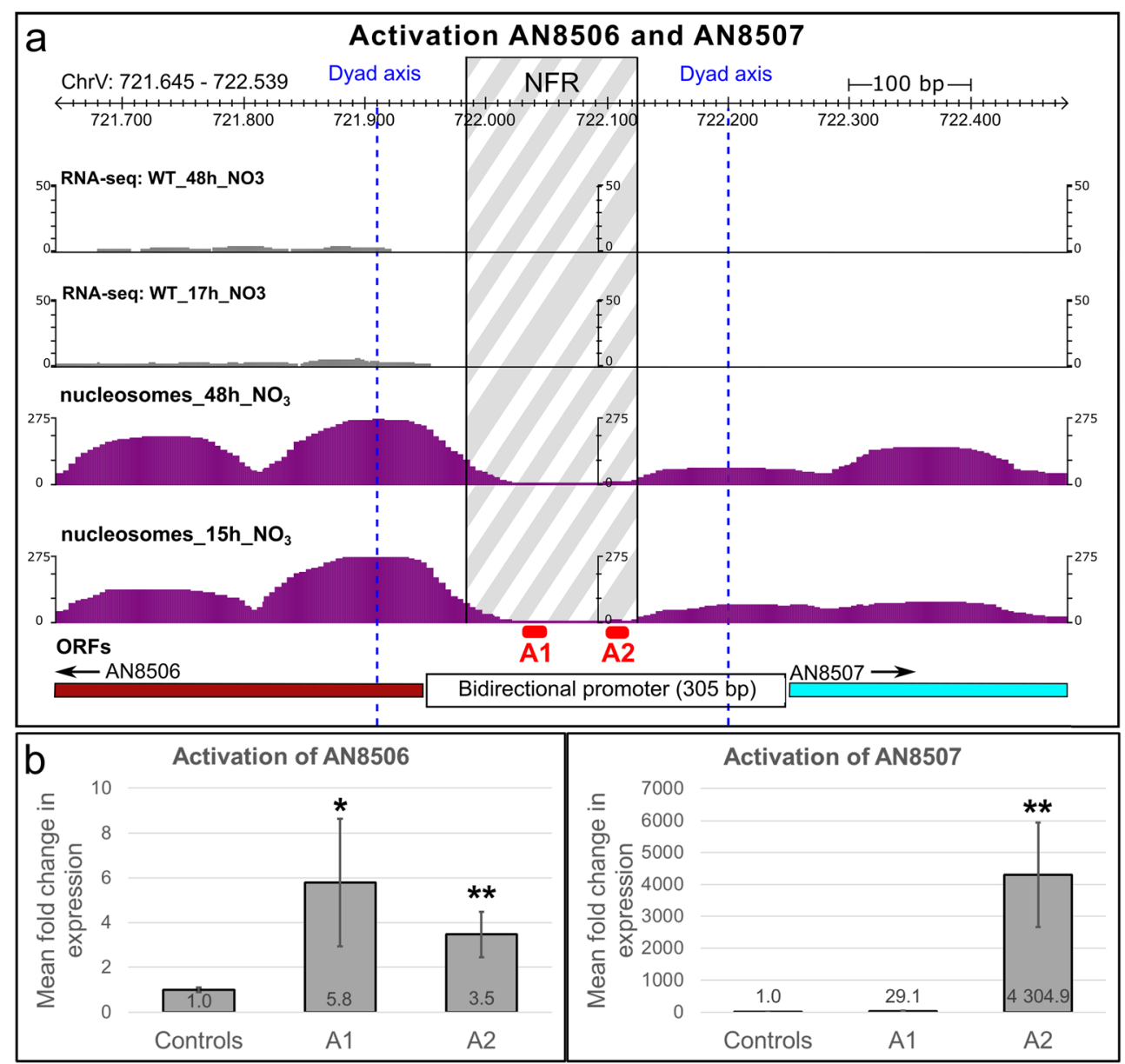

Fig. 6 Targeting of VPR-dCas9 to a bidirectional promoter and activation of its underlying genes AN8506 and AN8507. a The section shown comprises the begin of both genes AN8506 and AN8507 which share a bidirectional promoter of around 305 base pairs. The histograms show the mRNA profile (grey; Gacek-Matthews et al. (2016)) and the nucleosome positioning (purple) under nutrient-rich $(15 / 17 \mathrm{~h})$ and nutrient-depleted (48 h) conditions. The nucleosome-free region (NFR) is shown in grey white pattern which is delimited by the nucleosomal borders (set to an offset of 75 base pairs proximal to the dyad axis of the neighbouring

transcription. Although the promoter architecture suggests a bidirectionally active regulatory unit, the divergently transcribed AN8507 gene is far stronger activated than AN8506 by both $\mathrm{A} 1$ and $\mathrm{A} 2$. The fact that the activation potential of VPR-dCas9 is weaker on genes that are already moderately expressed supports this finding (Chavez et al. 2016). However, when comparing the effect of sgRNA A1 and A2 for the activation of gene AN8507, it gets apparent that even small changes in positioning of the activator lead to huge differences in the resulting gene activation. sgRNA A1 and A2 are only $50 \mathrm{bps}$ apart from each other. Despite this small genomic distance, VPR-dCas9 can upregulate gene AN8507 only 30 -fold when positioned by sgRNA A1 but is able to boost the transcription to 4.000 -fold when positioned by sgRNA A2 (compared with control strain VPR4!). While a molecular explanation for the huge difference in activation nucleosomes). The dyad axes are shown in vertical blue dashed lines and were set at the peak of the nucleosome histogram. Positions of sgRNAs are depicted in red (A1 and A2). b Expression data of the activation experiment: Controls: VPR4 (no sgRNA), A1: VPR4-A1-T1 to T3 | A2: VPR4-A2-T1 to T3. Three independent transformants per sgRNA (T1, T2, T3). Cultures were executed in triplicates. qPCR was performed in technical duplicates. Reproducibility was verified by two independent conductions of the experiment. The significance of the activation effect was verified by a Student's $t$ test $(* p<0.05 ; * * p<0.01)$

potential remains obscure, this case documents again how significant the impact of sgRNA positioning in relation to the (predicted) TSS of the target gene is.

Next, we also wanted to see whether upregulation of the TF AN8506 was sufficient to result in the expression of the NRPS-encoding gene AN8504. We therefore tested the same samples for transcription of the AN8504, but our RT-qPCR results did not detect any signal in these samples (data not shown). This indicates that expression of the TF or the transporter gene residing inside a BGC is not sufficient to turn on the backbone gene of the predicted cluster or that TF AN8506 does not positively regulate the backbone gene AN8504 at all. Using our novel VPR-dCas9 system and targeting different sgRNAs to all genes predicted to form the BGC would be a promising way to upregulate the whole cluster independently of a transcription factor. Therefore, it still could be possible to 
assign a product to this cluster and even to decipher the cognate biosynthetic pathway.

\section{Discussion}

Programmable transcriptional regulation is a powerful tool for the study of gene functions in general and for the activation of silent fungal BGCs in particular. The system presented here features a couple of advantages over traditional promoter replacements, in trans TF overexpression or heterologous expression strategies previously used to control gene expression.

\section{Keeping the genomic arrangement of the targeted locus intact}

One advantage of the system is that the genetic locus of interest (e.g. a predicted BGC for which no product is known so far) is not perturbed by introduced recombinant DNA. In traditional systems, artificially introduced constitutive or inducible promoters are recombined at the locus usually with a selection marker and vector sequences (Weld et al. 2006). These changes in genomic locus arrangements may lead to silencing of the introduced genetic material (e.g. selection marker) or nearby genes if the integration event is located directly in, or adjacent to a heterochromatic region due to position effect. This was shown in Drosophila (position effect variegation (Elgin and Reuter 2013; Henikoff 1990)), yeast and also filamentous fungi (telomere position effect (Allshire et al. 1994; Gottschling et al. 1990; Palmer and Keller 2010)). The VPR-dCas9 activator functions in the context of the native locus similar to a classical transcription activator. The sgRNA-dCas9 module functions quasi as DNA-binding domain of this synthetic factor, and by a simple change of the sgRNA sequence, it can easily be targeted at different positions in relation to the core promoter (TATA or CCAAT box) (Chang et al. 2013; Kinghorn and Turner 1992). It is well established that the interplay between the general transcription factor machinery which assembles at the core promoter as preinitiation complex (PIC) and the transcriptional activators binding to control elements upstream of the PIC is critical for promoter activity (Soutourina 2018). This is because the Mediator complex must be correctly situated to be able to connect the factors bound at the control elements to the PIC at the core promoter. If this arrangement is not optimal, promoter activity will be low (Dobi and Winston 2007). This aspect becomes particularly important when bidirectional promoters are targeted. Insertion of recombinant DNA during promoter replacement strategies disrupts co-regulation of the neighbouring genes risking regulatory off-target effects on the other gene with unknown consequences (loss- or gain-offunction phenotypes).

\section{Providing an optimal landing platform and distance for the activator to the general transcription machinery}

Stable interaction of an activator with DNA in promoter control elements is facilitated by binding of the factor within a NFR. Typical RNA-Pol II-transcribed fungal promoters feature such NFRs in a distance of average $\sim 200 \mathrm{bp}$ upstream of the start codon respectively from -111 to -5 of the TSSs (Chen et al. 2013; Yuan et al. 2005). As the NFR is flanked by nucleosome -1 at the promoter proximal and nucleosome -2 at the promoter distal side, the location of the NFR in relation to the core promoter is clearly also critical. The possibility to guide VPR-dCas9 to different positions within a promoter is another invaluable advantage of the presented system. Of course, to be able to provide an optimal landing platform for VPR-dCas9 in the NFR of a targeted gene promoter, a nucleosome positioning map of this locus needs to be available. Optimally, recording of these nucleosome maps by MNase-Seq should be done under the same conditions than the planned VPR-dCas9 activation because it is known that some genes have NFRs that are not static and thus nucleosomes may be differently positioned under changing environmental or developmental conditions (Lai and Pugh 2017). For example, the nitrate-responsive nucleosome shifting in the niiA-niaD intergenic region in A. nidulans is one of the paradigmatic examples for such regulation (Berger et al. 2006, 2008; Muro-Pastor et al. 1999). In any case, the possibility to move activator positioning sites to different positions in respect to the core promoter represents a unique advantage of the dCas9-based activators. Although the construction of a genome-wide nucleosome positioning map is not a widely implemented method in fungal laboratories, it is not a prerequisite to be able work with VPR-dCas9. The map only has to be generated once per strain and condition. This means that the map generated during this study can also be used by other research groups for the gRNA design to target other A. nidulans BGCs.

\section{Advantages of the dCas9-based system over tradi- tional TF overexpression strategies}

Several silent BGCs have been successfully activated by overexpression of the proprietary TF gene from a distant locus. The rationale of this approach is that a predicted TF-encoding gene lying next to genes probably forming a BGC is presumably the activator of all genes in its vicinity. Most likely, they all together would form a functional BGC, but so far, nobody was able to find conditions under which these genesincluding the TF-are expressed and hence the cluster product is not known. Therefore, the cluster-external forced expression of the TF may activate all genes (ideally the corresponding BGC) under its control and a novel product may be 
identified. However, there are important limitations to this approach: (i) many BGCs do not contain a predicted TF (Keller 2019). (ii) If the overexpressed TF requires condition-specific post-translational modifications (e.g. phosphorylation, protein processing) for its activity, but the corresponding conditions are not known, the TF will be present but inactive (Karin and Hunter 1995; Mingot et al. 2001). The VPR-dCas9 system presented here can circumvent these two problems as no PTMs are known to be required for its activity. (iii) In some cases, the upregulation of the cluster does not necessarily lead to product formation which is discussed in the next section.

\section{A possibility to activate the cluster stepwise and hence reveal the biosynthetic pathway}

Although we have not yet demonstrated its feasibility, the system provides the possibility to activate a BGC stepwise and under controlled timing conditions. The inducible expression of the VPR-dCas9 activator by addition of estrogen provides a simple control tool for this purpose. By designing a sgRNA-multiplex system similar to the procedure published by Nødvig and colleagues (Nødvig et al. 2018), one, two or more genes within a predicted BGC can be activated simultaneously. The activation of the core biosynthetic backbone gene (PKS, NRPS, prenyltransferases, terpene cyclases or hybrids thereof) in combination with different putative modifying or decorating enzymes and transporters will provide the possibility to elucidate different metabolic products originating from the cluster. If each step is accompanied by highresolution mass spectrometry of the resulting cultures, new products and their biosynthetic intermediates can be defined and assigned to the corresponding gene. The VPR-dCas9 system thus not only provides the possibility to study the effect of different gene combinations on the metabolic profile, but at the same time, the individual biosynthetic steps could be deciphered. As the system also supports the targeting of VPR-dCas9 to all genes of a BGC simultaneously, the forced overexpression of the whole cluster without a single promoter exchange is possible. Some clusters however do not produce a (detectable) compound despite all their genes being overexpressed. Possible reasons for this phenomenon could be that (i) the compound is only produced in small amounts that are below the limit of detection or are camouflaged by the background noise of other metabolites, (ii) an incomplete or mutated BGC that lost important functional elements during evolution or (iii) necessary precursor compounds (e.g. acetylcoA, amino acids, etc.) are in limiting concentrations or not available at all under the chosen growth condition (e.g. precursor is produced by another (inactive) cluster) (Chiang et al. 2016; Keller 2019). A good example is the interplay between the aspercryptin and the cichorine cluster of $A$. nidulans. The aspercryptin cluster (AN7884) was shown to be upregulated during cocultivation of A. nidulans with Streptomyces hygroscopicus (Schroeckh et al. 2009). No BGC product could however be detected. Another publication revealed that the cichorine cluster, which is only active on yeast extract sucrose medium, provides the precursor compound for the aspercryptin cluster (Chiang et al. 2016). Hence, without the active cichorine cluster, the active aspercryptin cluster cannot synthesise aspercryptin. This however was only detectable in an engineered dereplication strain which was missing the 8 most highly expressed secondary metabolite gene clusters and hence had a low level of background noise during metabolite measurement. These examples provide clear evidence that even with strong gene expression, there is not necessarily a detectable product emerging. The prospect that many silent BGCs of scientifically underrepresented fungal species, which are not easily amenable to molecular genetic methods, could be activated with the VPR-dCas9 system makes it a promising tool for future applications for novel drug discovery.

\section{A discovery platform suitable for many genes and fungi}

The transfer of this technique to other fungal species is highly likely as long as suitable vectors and reliable transformation protocols exist. Even for genetically less amenable fungi, VPR-dCas9 could be envisaged as an episomal version (i.e. AMA1) or by transformation of a ribonucleoprotein complex. This has been shown already for fungi to work for mutagenesis approaches (Foster et al. 2018; Kuivanen et al. 2019; Nødvig et al. 2018). For mutagenesis, however, only a low copy number of the Cas 9 enzyme is required and loss of the nuclease and sgRNA would even be an advantage after mutagenesis has been achieved. In contrast, it is likely that a much higher number of synthetic VPR-dCas9 activator molecules are required when it comes to act as efficient transcriptional regulator at one or more gene promoters. There is no experience to these approaches and future experiments will test its applicability. Application of the system obviously is not restricted to BGCs. It is likely to work as a shuttle system for chromatin and DNA-modifying enzymes altering nucleosomal PTM signatures and the chromatin architecture at the targeted locus. Fusions of dCas9 to such chromatin or DNA modifiers are thus a promising tool to study downstream pathways involved in epigenetic regulation. It should also be mentioned that $\mathrm{dCas} 9$ could be fused to a transcriptional repressor or used for transcriptional interference (CRISPRi). This way, also essential genes could be inactivated or knocked down in an inducible manner. This would open new opportunities to elucidate the essentiality of the gene of interest with respect to the developmental state of the fungus (Hilton et al. 2015; Larson et al. 2013). 


\section{Guide RNA design as a key factor for activation}

The design and positioning of the sgRNAs (i.e. position of VPR-dCas9 in the genome) is a crucial factor for proper function. The majority of Cas9 applications concern the cutting of one or both DNA strands within a gene body (Ran et al. 2013). Once the Cas9 protein can cause a nick or a double-strand brake that is erroneously repaired by the DNA repair machinery, presence of Cas9 at the locus is neither necessary nor likely anymore (Brinkman et al. 2018). The story is however different for the activator VPR-dCas9. Not only is the protein bigger, which can lead to steric hindrances at the desired locus, but the outcome of an experiment is not determined by a one-time event (i.e. erroneous DNA repair) but is the result of a persistent presence of the activator at the desired locus. The residence time of dCas9 at the target locus also greatly depends on the guide RNA (Ma et al. 2016). Many transcription-relevant proteins and their binding sites (e.g. RNA-Pol II complex, nucleosomes, transcription factors, CCAAT box binding proteins, TATA box) are in the promoter which on the one hand should not be blocked, but on the other hand, can interfere with the VPR-dCas9 activator (Chen et al. 2013; Mao and Chen 2019; Nikolov and Burley 1997). Furthermore, the activator has to be positioned at a location where it can actually trigger transcriptional activation. However, if the sgRNA is designed in a way which positions VPR-dCas9 too close to the TSS, the transcription could get blocked or reduced due to CRISPRi effects (Larson et al. 2013). Therefore, the chromatin and nucleosome map at the target location can have a major impact on accessibility of VPR-dCas9 to the DNA and therefore its efficiency (Chen et al. 2016; Chung et al. 2020). Many promoters contain loosely attached nucleosomes or even NFRs which could be good entry points for VPR-dCas9 (Yadon et al. 2010).

\section{Limitations of the system (as tested so far)}

Despite our promising first results and hypothetical great possibilities, during our work, we observed several important limitations and possible hurdles for an establishment of the system as efficient expression platform. The shortcomings we experienced were, e.g. quite strong variation in expression strengths. For example, the activation pattern of $m d p G$ is similar to the induction of $m d p E$ but overall expression is much weaker. There is no obvious explanation for that. However, one possibility could be that $m d p A$ - an important co-activator for the monodictyphenone BGC (Chiang et al. 2010) - was not targeted and activated together with $m d p E$. It was shown that the cluster activity is significantly reduced if $m d p A$ is deleted. It is still not clear if $m d p A$ is under the transcriptional control of MdpE. It could also be that they are regulated independently and that complex formation of $\mathrm{MdpE}$ and $\mathrm{MdpA}$ is needed to exert its full activating function on the other genes of the cluster. Such a scenario would be consistent with our results. In addition, the strength of activation depends on the position of the gRNA. In case of the very short bidirectional promoter between genes AN8506 and AN8507, even a distance of 50 bps can change the activation potential for about a thousand-fold. It is unlikely that only the short distance accounts for the difference in activation. It seems more likely that other (regulatory) proteins or protein complexes are either hindered during assembly by VPR-dCas9 or, vice versa, that the activator is not able to access the DNA properly. To know the exact proteomic composition at the promoter would help evaluating the outcome of the experiments and give more insight about efficient positioning of gRNAs for optimal gene activation.

Proper sgRNA design and positioning is probably the most crucial aspect of this system. As observed in this study and a study conducted by Li et al. (2017), it is apparent that the distance of the activator to the TSS is the key element to a successful activation which also could lead to a long trial and error phase before finding the proper sgRNA. This would especially mean a huge drawback in case of multiplex sgRNA experiments which would negate some of the benefits of this method. To circumvent this problem and facilitate efficient designing of guide RNAs in the future, we plan to analyse many different promoters by applying several sgRNAs individually (i.e. "guide RNA walking" along the promoter) and assessing the resulting activation. The aim here will be to find common patterns where VPR-dCas9 can effectively be deployed. The outlook is very promising as Li et al. (2017) did a similar experiment in plants. They tested multiple sgRNAs on several promoters in Arabidopsis thaliana and found out that the maximal activation occurred between 42 and 210 base pairs upstream of the TSS with a tendency towards regions below 110 base pairs. A proper analysis of this aspect will not only benefit transcriptional activator systems based on dCas9 in fungi but also in other Eukarya.

The fact that activations that range in the thousand folds compared with the basal, non-induced level can be achieved makes it a very promising tool for forced gene activation approaches. To effectively use this tool, the proper design of guide RNAs has to be further studied and optimised. The finding of patterns for in silico prediction of best sgRNAbinding sites would demand in depth research on more promoter/gene types with larger experimental setups ("guide RNA walking" along the promoter) and detailed promoter characterisation like local proteomic composition analyses at the targeted promoters.

Acknowledgements We want to thank colleagues from the Perrimon laboratory (Harvard Medical School, Boston, MA, USA) for sending us the vectors for the amplification of the $V P R$ gene, as well as colleagues from the Leonardt laboratory (LMU Munich, Martinsried, Germany) who sent us the plasmids for the amplification of $d \operatorname{Cas} 9$, and from the Mortensen laboratory (Technical University of Denmark, Søltofts Plads, 
Kongens Lyngby, Denmark) that provided the templates of the sgRNA cassette. We are also thankful to Matthias Steiger and Michael Sauer (BOKU University) for help with the coxA promoter design. Many thanks also to Dragana Bandian (AIT, Austrian Institute of Technology) who provided the gDNAs of fungal wild-type isolates for plasmid construction.

Authors' contributions Study design: AS, LS and JS. Performed research: AS, LS, AG and MS. Analysis of data: AS, HB and MS. Writing of manuscript: AS, LS and JS. All authors read and approved the manuscript.

Funding Open access funding provided by Austrian Science Fund (FWF). Work was funded by grant Nr. K3-G-2/026-2013 "Bioactive Microbial Metabolites" from the NFB Lower Austria Science Fund and grant P32790 "ChroCosm" from the FWF Austrian Science Fund to JS and by the "Wirtschaftskammerpreis 2018" from the WKO Wien to AS.

Data availability RNA-seq data are available at NCBI GEO under the accession number GSE72126 (Gacek-Matthews et al. 2016).

MNase-seq data are available at NCBI SRA under the accession number SRR12336645 and SRR12336644.

All strains are available upon request from the lab of the corresponding author.

\section{Compliance with ethical standards}

This article does not contain any studies with human participants or animals performed by any of the authors.

Conflict of interest The authors declare that they have no conflict of interest.

Ethics approval Not applicable.

Consent to participate Not applicable.

Consent for publication Not applicable.

Code availability Not applicable

Open Access This article is licensed under a Creative Commons Attribution 4.0 International License, which permits use, sharing, adaptation, distribution and reproduction in any medium or format, as long as you give appropriate credit to the original author(s) and the source, provide a link to the Creative Commons licence, and indicate if changes were made. The images or other third party material in this article are included in the article's Creative Commons licence, unless indicated otherwise in a credit line to the material. If material is not included in the article's Creative Commons licence and your intended use is not permitted by statutory regulation or exceeds the permitted use, you will need to obtain permission directly from the copyright holder. To view a copy of this licence, visit http://creativecommons.org/licenses/by/4.0/.

\section{References}

Adams MD, Celniker SE, Holt RA, Evans CA, Gocayne JD, Amanatides PG, Scherer SE, Li PW, Hoskins RA, Galle RF, George RA, Lewis SE, Richards S, Ashburner M, Henderson SN, Sutton GG, Wortman JR, Yandell MD, Zhang Q, Chen LX, Brandon RC, Rogers YH,
Blazej RG, Champe M, Pfeiffer BD, Wan KH, Doyle C, Baxter EG, Helt G, Nelson CR, Gabor GL, Abril JF, Agbayani A, An HJ, Andrews-Pfannkoch C, Baldwin D, Ballew RM, Basu A, Baxendale J, Bayraktaroglu L, Beasley EM, Beeson KY, Benos PV, Berman BP, Bhandari D, Bolshakov S, Borkova D, Botchan MR, Bouck J, Brokstein P, Brottier P, Burtis KC, Busam DA, Butler H, Cadieu E, Center A, Chandra I, Cherry JM, Cawley S, Dahlke C, Davenport LB, Davies P, de Pablos B, Delcher A, Deng Z, Mays AD, Dew I, Dietz SM, Dodson K, Doup LE, Downes M, DuganRocha S, Dunkov BC, Dunn P, Durbin KJ, Evangelista CC, Ferraz C, Ferriera S, Fleischmann W, Fosler C, Gabrielian AE, Garg NS, Gelbart WM, Glasser K, Glodek A, Gong F, Gorrell JH, Gu Z, Guan P, Harris M, Harris NL, Harvey D, Heiman TJ, Hernandez JR, Houck J, Hostin D, Houston KA, Howland TJ, Wei MH, Ibegwam C, Jalali M, Kalush F, Karpen GH, Ke Z, Kennison JA, Ketchum KA, Kimmel BE, Kodira CD, Kraft C, Kravitz S, Kulp D, Lai Z, Lasko P, Lei Y, Levitsky AA, Li J, Li Z, Liang Y, Lin X, Liu X, Mattei B, McIntosh TC, McLeod MP, McPherson D, Merkulov G, Milshina NV, Mobarry C, Morris J, Moshrefi A, Mount SM, Moy M, Murphy B, Murphy L, Muzny DM, Nelson DL, Nelson DR, Nelson KA, Nixon K, Nusskern DR, Pacleb JM, Palazzolo M, Pittman GS, Pan S, Pollard J, Puri V, Reese MG, Reinert K, Remington K, Saunders RD, Scheeler F, Shen H, Shue BC, SidenKiamos I, Simpson M, Skupski MP, Smith T, Spier E, Spradling AC, Stapleton M, Strong R, Sun E, Svirskas R, Tector C, Turner R, Venter E, Wang AH, Wang X, Wang ZY, Wassarman DA, Weinstock GM, Weissenbach J, Williams SM, WoodageT WKC, Wu D, Yang S, Yao QA, Ye J, Yeh RF, Zaveri JS, Zhan M, Zhang G, Zhao Q, Zheng L, Zheng XH, Zhong FN, Zhong W, Zhou X, Zhu S, Zhu X, Smith HO, Gibbs RA, Myers EW, Rubin GM, Venter JC (2000) The genome sequence of Drosophila melanogaster. Science 287(5461):2185-2195. https://doi.org/10.1126/science. 287.5461.2185

Aguiar TQ, Dinis C, Domingues L (2014) Cre-loxP-based system for removal and reuse of selection markers in Ashbya gossypii targeted engineering. Fungal Genet Biol 68:1-8. https://doi.org/10.1016/j. fgb.2014.04.009

Ahuja M, Chiang YM, Chang SL, Praseuth MB, Entwistle R, Sanchez JF, Lo HC, Yeh HH, Oakley BR, Wang CC (2012) Illuminating the diversity of aromatic polyketide synthases in Aspergillus nidulans. $\mathrm{J}$ Am Chem Soc 134(19):8212-8221. https://doi.org/10.1021/ ja3016395

Allshire RC, Javerzat J-P, Redhead NJ, Cranston G (1994) Position effect variegation at fission yeast centromeres. Cell 76(1):157-169. https:// doi.org/10.1016/0092-8674(94)90180-5

Andersen MR, Nielsen JB, Klitgaard A, Petersen LM, Zachariasen M, Hansen TJ, Blicher LH, Gotfredsen CH, Larsen TO, Nielsen KF, Mortensen UH (2013) Accurate prediction of secondary metabolite gene clusters in filamentous fungi. Proc Natl Acad Sci U S A 110(1): E99-E107. https://doi.org/10.1073/pnas.1205532110

Arabidopsis Genome I (2000) Analysis of the genome sequence of the flowering plant Arabidopsis thaliana. Nature 408(6814):796-815. https://doi.org/10.1038/35048692

Bachleitner S, Sorensen JL, Gacek-Matthews A, Sulyok M, Studt L, Strauss J (2019) Evidence of a demethylase-independent role for the H3K4-specific histone demethylases in Aspergillus nidulans and Fusarium graminearum secondary metabolism. Front Microbiol 10:1759. https://doi.org/10.3389/fmicb.2019.01759

Barratt RW, Johnson GB, Ogata WN (1965) Wild-type and mutant stocks of Aspergillus nidulans. Genetics 52(1):233-246

Bashyal BM, Rawat K, Sharma S, Kulshreshtha D, Gopala Krishnan S, Singh AK, Dubey H, Solanke AU, Sharma TR, Aggarwal R (2017) Whole genome sequencing of Fusarium fujikuroi provides insight into the role of secretory proteins and cell wall degrading enzymes in causing bakanae disease of rice. Front Plant Sci 8:2013. https://doi. org/10.3389/fpls.2017.02013 
Berger H, Pachlinger R, Morozov I, Goller S, Narendja F, Caddick M, Strauss J (2006) The GATA factor AreA regulates localization and in vivo binding site occupancy of the nitrate activator NirA. Mol Microbiol 59(2):433-446. https://doi.org/10.1111/j.1365-2958. 2005.04957.x

Berger H, Basheer A, Bock S, Reyes-Dominguez Y, Dalik T, Altmann F, Strauss J (2008) Dissecting individual steps of nitrogen transcription factor cooperation in the Aspergillus nidulans nitrate cluster. Mol Microbiol 69(6):1385-1398. https://doi.org/10.1111/j.1365-2958. 2008.06359.x

Bergmann S, Schumann J, Scherlach K, Lange C, Brakhage AA, Hertweck C (2007) Genomics-driven discovery of PKS-NRPS hybrid metabolites from Aspergillus nidulans. Nat Chem Biol 3(4): 213-217. https://doi.org/10.1038/nchembio869

Bode HB, Bethe B, Höfs R, Zeeck A (2002) Big effects from small changes: possible ways to explore nature's chemical diversity. ChemBioChem 3(7):619-627

Bödi S (2008) Development of an estrogen-regulable knock-down system in Aspergillus nidulans. Thesis/Dissertation, University of Natural Resources and Life Sciences, Vienna

Bok JW, Hoffmeister D, Maggio-Hall LA, Murillo R, Glasner JD, Keller NP (2006) Genomic mining for Aspergillus natural products. Chem Biol 13(1):31-37. https://doi.org/10.1016/j.chembiol.2005.10.008

Bok JW, Chiang YM, Szewczyk E, Reyes-Dominguez Y, Davidson AD, Sanchez JF, Lo HC, Watanabe K, Strauss J, Oakley BR, Wang CC, Keller NP (2009) Chromatin-level regulation of biosynthetic gene clusters. Nat Chem Biol 5(7):462-464. https://doi.org/10.1038/ nchembio. 177

Bok JW, Soukup AA, Chadwick E, Chiang YM, Wang CC, Keller NP (2013) VeA and MvlA repression of the cryptic orsellinic acid gene cluster in Aspergillus nidulans involves histone 3 acetylation. Mol Microbiol 89(5):963-974. https://doi.org/10.1111/mmi.12326

Bok JW, Ye R, Clevenger KD, Mead D, Wagner M, Krerowicz A, Albright JC, Goering AW, Thomas PM, Kelleher NL, Keller NP, Wu CC (2015) Fungal artificial chromosomes for mining of the fungal secondary metabolome. BMC Genomics 16:343. https:// doi.org/10.1186/s12864-015-1561-x

Brakhage AA (2013) Regulation of fungal secondary metabolism. Nat Rev Microbiol 11(1):21-32. https://doi.org/10.1038/nrmicro2916

Brakhage AA, Schroeckh V (2011) Fungal secondary metabolites - strategies to activate silent gene clusters. Fungal Genet Biol 48(1):1522. https://doi.org/10.1016/j.fgb.2010.04.004

Brandhoff B, Simon A, Dornieden A, Schumacher J (2017) Regulation of conidiation in Botrytis cinerea involves the light-responsive transcriptional regulators BcLTF3 and BcREG1. Curr Genet 63(5): 931-949. https://doi.org/10.1007/s00294-017-0692-9

Brefort T, Doehlemann G, Mendoza-Mendoza A, Reissmann S, Djamei A, Kahmann R (2009) Ustilago maydis as a pathogen. Annu Rev Phytopathol 47:423-445. https://doi.org/10.1146/annurev-phyto080508-081923

Brinkman EK, Chen T, de Haas M, Holland HA, Akhtar W, van Steensel B (2018) Kinetics and fidelity of the repair of Cas9-induced doublestrand DNA breaks. Mol Cell 70(5):801-813 e6. https://doi.org/10. 1016/j.molcel.2018.04.016

Bromann K, Toivari M, Viljanen K, Vuoristo A, Ruohonen L, NakariSetala T (2012) Identification and characterization of a novel diterpene gene cluster in Aspergillus nidulans. PLoS One 7(4):e35450. https://doi.org/10.1371/journal.pone.0035450

Brown DW, Yu JH, Kelkar HS, Fernandes M, Nesbitt TC, Keller NP, Adams TH, Leonard TJ (1996) Twenty-five coregulated transcripts define a sterigmatocystin gene cluster in Aspergillus nidulans. Proc Natl Acad Sci U S A 93(4):1418-1422. https://doi.org/10.1073/ pnas.93.4.1418

Brückner B, Unkles SE, Weltring K, Kinghorn JR (1992) Transformation of Gibberella fujikuroi: effect of the Aspergillus nidulans AMA1 sequence on frequency and integration. Curr Genet 22(4):313-316. https://doi.org/10.1007/BF00317927

Cenis JL (1992) Rapid extraction of fungal DNA for PCR amplification. Nucleic Acids Res 20(9):2380. https://doi.org/10.1093/nar/20.9. 2380

Cerqueira GC, Arnaud MB, Inglis DO, Skrzypek MS, Binkley G, Simison M, Miyasato SR, Binkley J, Orvis J, Shah P, Wymore F, Sherlock G, Wortman JR (2014) The Aspergillus Genome Database: multispecies curation and incorporation of RNA-Seq data to improve structural gene annotations. Nucleic Acids Res 42(Database issue):D705-D710. https://doi.org/10.1093/nar/ gkt1029

Chang LK, Chung JY, Hong YR, Ichimura T, Nakao M, Liu ST (2005) Activation of Sp1-mediated transcription by Rta of Epstein-Barr virus via an interaction with MCAF1. Nucleic Acids Res 33(20): 6528-6539. https://doi.org/10.1093/nar/gki956

Chang LW, Viader A, Varghese N, Payton JE, Milbrandt J, Nagarajan R (2013) An integrated approach to characterize transcription factor and microRNA regulatory networks involved in Schwann cell response to peripheral nerve injury. BMC Genomics 14:84. https:// doi.org/10.1186/1471-2164-14-84

Chavez A, Scheiman J, Vora S, Pruitt BW, Tuttle M, PRI E, Lin S, Kiani S, Guzman CD, Wiegand DJ, Ter-Ovanesyan D, Braff JL, Davidsohn N, Housden BE, Perrimon N, Weiss R, Aach J, Collins JJ, Church GM (2015) Highly efficient Cas9-mediated transcriptional programming. Nat Methods 12(4):326-328. https://doi.org/ 10.1038/nmeth. 3312

Chavez A, Tuttle M, Pruitt BW, Ewen-Campen B, Chari R, TerOvanesyan D, Haque SJ, Cecchi RJ, Kowal EJK, Buchthal J, Housden BE, Perrimon N, Collins JJ, Church G (2016) Comparison of Cas9 activators in multiple species. Nat Methods 13(7):563-567. https://doi.org/10.1038/nmeth.3871

Chen K, Wilson MA, Hirsch C, Watson A, Liang S, Lu Y, Li W, Dent SY (2013) Stabilization of the promoter nucleosomes in nucleosomefree regions by the yeast Cyc8-Tup1 corepressor. Genome Res 23(2):312-322. https://doi.org/10.1101/gr.141952.112

Chen X, Rinsma M, Janssen JM, Liu J, Maggio I, Goncalves MA (2016) Probing the impact of chromatin conformation on genome editing tools. Nucleic Acids Res 44(13):6482-6492. https://doi.org/10. 1093/nar/gkw524

Chiang YM, Szewczyk E, Nayak T, Davidson AD, Sanchez JF, Lo HC, Ho WY, Simityan H, Kuo E, Praseuth A, Watanabe K, Oakley BR, Wang CC (2008) Molecular genetic mining of the Aspergillus secondary metabolome: discovery of the emericellamide biosynthetic pathway. Chem Biol 15(6):527-532. https://doi.org/10.1016/j. chembiol.2008.05.010

Chiang YM, Szewczyk E, Davidson AD, Keller N, Oakley BR, Wang CC (2009) A gene cluster containing two fungal polyketide synthases encodes the biosynthetic pathway for a polyketide, asperfuranone, in Aspergillus nidulans. J Am Chem Soc 131(8): 2965-2970. https://doi.org/10.1021/ja8088185

Chiang YM, Szewczyk E, Davidson AD, Entwistle R, Keller NP, Wang CC, Oakley BR (2010) Characterization of the Aspergillus nidulans monodictyphenone gene cluster. Appl Environ Microbiol 76(7): 2067-2074. https://doi.org/10.1128/AEM.02187-09

Chiang YM, Ahuja M, Oakley CE, Entwistle R, Asokan A, Zutz C, Wang CC, Oakley BR (2016) Development of genetic dereplication strains in Aspergillus nidulans results in the discovery of Aspercryptin. Angew Chem Int Ed Engl 55(5):1662-1665. https://doi.org/10. 1002/anie.201507097

Christianson TW, Sikorski RS, Dante M, Shero JH, Hieter P (1992) Multifunctional yeast high-copy-number shuttle vectors. Gene 110(1):119-122. https://doi.org/10.1016/0378-1119(92)90454-w

Chujo T, Scott B (2014) Histone H3K9 and H3K27 methylation regulates fungal alkaloid biosynthesis in a fungal endophyte-plant symbiosis. Mol Microbiol 92(2):413-434. https://doi.org/10.1111/mmi.12567 
Chung CH, Allen AG, Sullivan NT, Atkins A, Nonnemacher MR, Wigdahl B, Dampier W (2020) Computational analysis concerning the impact of DNA accessibility on CRISPR-Cas9 cleavage efficiency. Mol Ther 28(1):19-28. https://doi.org/10.1016/j.ymthe. 2019.10.008

Clevenger KD, Bok JW, Ye R, Miley GP, Verdan MH, Velk T, Chen C, Yang K, Robey MT, Gao P, Lamprecht M, Thomas PM, Islam MN, Palmer JM, Wu CC, Keller NP, Kelleher NL (2017) A scalable platform to identify fungal secondary metabolites and their gene clusters. Nat Chem Biol 13(8):895-901. https://doi.org/10.1038/ nchembio. 2408

Connolly LR, Smith KM, Freitag M (2013) The Fusarium graminearum histone H3 K27 methyltransferase KMT6 regulates development and expression of secondary metabolite gene clusters. PLoS Genet 9(10):e1003916. https://doi.org/10.1371/journal.pgen.1003916

Consortium CS (1998) Genome sequence of the nematode C. elegans: a platform for investigating biology. Science 282(5396):2012-2018. https://doi.org/10.1126/science.282.5396.2012

Cuomo CA, Guldener U, Xu JR, Trail F, Turgeon BG, Di Pietro A, Walton JD, Ma LJ, Baker SE, Rep M, Adam G, Antoniw J, Baldwin T, Calvo S, Chang YL, Decaprio D, Gale LR, Gnerre S, Goswami RS, Hammond-Kosack K, Harris LJ, Hilburn K, Kennell JC, Kroken S, Magnuson JK, Mannhaupt G, Mauceli E, Mewes HW, Mitterbauer R, Muehlbauer G, Munsterkotter M, Nelson D, O’Donnell K, Ouellet T, Qi W, Quesneville H, Roncero MI, Seong KY, Tetko IV, Urban M, Waalwijk C, Ward TJ, Yao J, Birren BW, Kistler HC (2007) The Fusarium graminearum genome reveals a link between localized polymorphism and pathogen specialization. Science 317(5843):1400-1402. https://doi.org/10.1126/science. 1143708

Dobi KC, Winston F (2007) Analysis of transcriptional activation at a distance in Saccharomyces cerevisiae. Mol Cell Biol 27(15):55755586. https://doi.org/10.1128/MCB.00459-07

Eisendle M, Oberegger H, Zadra I, Haas H (2003) The siderophore system is essential for viability of Aspergillus nidulans: functional analysis of two genes encoding 1-ornithine N 5-monooxygenase (sidA) and a non-ribosomal peptide synthetase (sidC). Mol Microbiol 49(2):359-375. https://doi.org/10.1046/j.1365-2958.2003.03586.x

Elgin SC, Reuter G (2013) Position-effect variegation, heterochromatin formation, and gene silencing in Drosophila. Cold Spring Harb Perspect Biol 5(8):a017780. https://doi.org/10.1101/cshperspect. a017780

Ezkurdia I, Juan D, Rodriguez JM, Frankish A, Diekhans M, Harrow J, Vazquez J, Valencia A, Tress ML (2014) Multiple evidence strands suggest that there may be as few as 19,000 human protein-coding genes. Hum Mol Genet 23(22):5866-5878. https://doi.org/10.1093/ hmg/ddu309

Foster AJ, Martin-Urdiroz M, Yan X, Wright HS, Soanes DM, Talbot NJ (2018) CRISPR-Cas9 ribonucleoprotein-mediated co-editing and counterselection in the rice blast fungus. Sci Rep 8(1):14355. https://doi.org/10.1038/s41598-018-32702-w

Gacek A, Strauss J (2012) The chromatin code of fungal secondary metabolite gene clusters. Appl Microbiol Biotechnol 95(6):1389-1404. https://doi.org/10.1007/s00253-012-4208-8

Gacek-Matthews A, Berger H, Sasaki T, Wittstein K, Gruber C, Lewis ZA, Strauss J (2016) KdmB, a jumonji histone H3 demethylase, regulates genome-wide $\mathrm{H} 3 \mathrm{~K} 4$ trimethylation and is required for normal induction of secondary metabolism in Aspergillus nidulans. PLoS Genet 12(8):e1006222. https://doi.org/10.1371/journal.pgen. 1006222

Galagan JE, Calvo SE, Cuomo C, Ma LJ, Wortman JR, Batzoglou S, Lee SI, Basturkmen M, Spevak CC, Clutterbuck J, Kapitonov V, Jurka J, Scazzocchio C, Farman M, Butler J, Purcell S, Harris S, Braus GH, Draht O, Busch S, D'Enfert C, Bouchier C, Goldman GH, BellPedersen D, Griffiths-Jones S, Doonan JH, Yu J, Vienken K, Pain A, Freitag M, Selker EU, Archer DB, Penalva MA, Oakley BR,
Momany M, Tanaka T, Kumagai T, Asai K, Machida M, Nierman WC, Denning DW, Caddick M, Hynes M, Paoletti M, Fischer R, Miller B, Dyer P, Sachs MS, Osmani SA, Birren BW (2005) Sequencing of Aspergillus nidulans and comparative analysis with A. fumigatus and A. oryzae. Nature 438(7071):1105-1115. https:// doi.org/10.1038/nature04341

García-Estrada C, Domínguez-Santos R, Kosalková K, Martín J-F (2018) Transcription factors controlling primary and secondary metabolism in filamentous fungi: the $\beta$-lactam paradigm. Fermentation $4(2)$. https://doi.org/10.3390/fermentation4020047

Gerke J, Braus GH (2014) Manipulation of fungal development as source of novel secondary metabolites for biotechnology. Appl Microbiol Biotechnol 98(20):8443-8455. https://doi.org/10.1007/s00253-014$5997-8$

Gerke J, Bayram O, Feussner K, Landesfeind M, Shelest E, Feussner I, Braus GH (2012) Breaking the silence: protein stabilization uncovers silenced biosynthetic gene clusters in the fungus Aspergillus nidulans. Appl Environ Microbiol 78(23):8234-8244. https://doi.org/10.1128/AEM.01808-12

Gottschling DE, Aparicio OM, Billington BL, Zakian VA (1990) Position effect at $S$. cerevisiae telomeres: reversible repression of Pol II transcription. Cell 63(4):751-762. https://doi.org/10.1016/ 0092-8674(90)90141-Z

Graham-Taylor C, Kamphuis LG, Derbyshire MC (2020) A detailed in silico analysis of secondary metabolite biosynthesis clusters in the genome of the broad host range plant pathogenic fungus Sclerotinia sclerotiorum. BMC Genomics 21(1):7. https://doi.org/10.1186/ s12864-019-6424-4

Grau MF, Entwistle R, Chiang YM, Ahuja M, Oakley CE, Akashi T, Wang CCC, Todd RB, Oakley BR (2018) Hybrid transcription factor engineering activates the silent secondary metabolite gene cluster for (+)-Asperlin in Aspergillus nidulans. ACS Chem Biol 13(11): 3193-3205. https://doi.org/10.1021/acschembio.8b00679

Grau MF, Entwistle R, Oakley CE, Wang CCC, Oakley BR (2019) Overexpression of an LaeA-like methyltransferase upregulates secondary metabolite production in Aspergillus nidulans. ACS Chem Biol 14(7):1643-1651. https://doi.org/10.1021/acschembio. $9 \mathrm{~b} 00380$

Hai Y, Huang AM, Tang Y (2019) Structure-guided function discovery of an NRPS-like glycine betaine reductase for choline biosynthesis in fungi. Proc Natl Acad Sci U S A 116(21):10348-10353. https:// doi.org/10.1073/pnas.1903282116

Hall DB, Struhl K (2002) The VP16 activation domain interacts with multiple transcriptional components as determined by proteinprotein cross-linking in vivo. J Biol Chem 277(48):46043-46050. https://doi.org/10.1074/jbc.M208911200

Hansen FT, Gardiner DM, Lysoe E, Fuertes PR, Tudzynski B, Wiemann P, Sondergaard TE, Giese H, Brodersen DE, Sorensen JL (2015) An update to polyketide synthase and non-ribosomal synthetase genes and nomenclature in Fusarium. Fungal Genet Biol 75:20-29. https://doi.org/10.1016/j.fgb.2014.12.004

Hardwick JM, Tse L, Applegren N, Nicholas J, Veliuona MA (1992) The Epstein-Barr virus R transactivator (Rta) contains a complex, potent activation domain with properties different from those of VP16. J Virol 66(9):5500-5508

Henikoff S (1990) Position-effect variegation after 60 years. Tr Genet 6: 422-426. https://doi.org/10.1016/0168-9525(90)90304-o

Hilton IB, D'Ippolito AM, Vockley CM, Thakore PI, Crawford GE, Reddy TE, Gersbach CA (2015) Epigenome editing by a CRISPR-Cas9-based acetyltransferase activates genes from promoters and enhancers. Nat Biotechnol 33(5):510-517. https://doi. org/10.1038/nbt.3199

Hollingsworth CR, Motteberg CD, Wiersma JV, Atkinson LM (2008) Agronomic and economic responses of spring wheat to management of Fusarium head blight. Plant Dis 92(9):1339-1348. https://doi. org/10.1094/PDIS-92-9-1339 
Inglis DO, Binkley J, Skrzypek MS, Arnaud MB, Cerqueira GC, Shah P, Wymore F, Wortman JR, Sherlock G (2013) Comprehensive annotation of secondary metabolite biosynthetic genes and gene clusters of Aspergillus nidulans, A. fumigatus, A. niger and A. oryzae. BMC Microbiol 13:91. https://doi.org/10.1186/1471-2180-13-91

Ishikawa N, Tanaka H, Koyama F, Noguchi H, Wang CC, Hotta K, Watanabe K (2014) Non-heme dioxygenase catalyzes atypical oxidations of 6,7-bicyclic systems to form the 6,6-quinolone core of viridicatin-type fungal alkaloids. Angew Chem Int Ed Engl 53(47): 12880-12884. https://doi.org/10.1002/anie.201407920

Karin M, Hunter T (1995) Transcriptional control by protein phosphorylation: signal transmission from the cell surface to the nucleus. Curr Biol 5(7):747-757. https://doi.org/10.1016/s0960-9822(95)00151-5

Kawahara Y, de la Bastide M, Hamilton JP, Kanamori H, McCombie WR, Ouyang S, Schwartz DC, Tanaka T, Wu J, Zhou S, Childs KL, Davidson RM, Lin H, Quesada-Ocampo L, Vaillancourt B, Sakai H, Lee SS, Kim J, Numa H, Itoh T, Buell CR, Matsumoto T (2013) Improvement of the Oryza sativa Nipponbare reference genome using next generation sequence and optical map data. Rice (N Y) 6(1):4. https://doi.org/10.1186/1939-8433-6-4

Keller NP (2019) Fungal secondary metabolism: regulation, function and drug discovery. Nat Rev Microbiol 17(3):167-180. https://doi.org/ 10.1038/s41579-018-0121-1

Kinghorn JR, Turner G (1992) Applied molecular genetics of filamentous fungi. Springer Netherlands

Kubodera T, Yamashita N, Nishimura A (2002) Transformation of Aspergillus sp. and Trichoderma reesei using the pyrithiamine resistance gene (ptrA) of Aspergillus oryzae. Biosci Biotechnol Biochem 66(2):404 406. https://doi.org/10.1271/bbb.66.404

Kuivanen J, Korja V, Holmstrom S, Richard P (2019) Development of microtiter plate scale CRISPR/Cas9 transformation method for Aspergillus niger based on in vitro assembled ribonucleoprotein complexes. Fungal Biol Biotechnol 6:3. https://doi.org/10.1186/ s40694-019-0066-9

Lai WKM, Pugh BF (2017) Understanding nucleosome dynamics and their links to gene expression and DNA replication. Nat Rev Mol Cell Biol 18(9):548-562. https://doi.org/10.1038/nrm.2017.47

Larson MH, Gilbert LA, Wang X, Lim WA, Weissman JS, Qi LS (2013) CRISPR interference (CRISPRi) for sequence-specific control of gene expression. Nat Protoc 8(11):2180-2196. https://doi.org/10. 1038/nprot.2013.132

Lecoq L, Raiola L, Chabot PR, Cyr N, Arseneault G, Legault P, Omichinski JG (2017) Structural characterization of interactions between transactivation domain 1 of the p65 subunit of NF-KB and transcription regulatory factors. Nucleic Acids Res 45(9):5564 5576. https://doi.org/10.1093/nar/gkx146

Lee S, Hahn S (1995) Model for binding of transcription factor TFIIB to the TBP-DNA complex. Nature 376(6541):609-612. https://doi. org/10.1038/376609a0

Li Z, Zhang D, Xiong X, Yan B, Xie W, Sheen J, Li JF (2017) A potent Cas9-derived gene activator for plant and mammalian cells. Nat Plants 3(12):930-936. https://doi.org/10.1038/s41477-017-0046-0

Lin S, Ewen-Campen B, Ni X, Housden BE, Perrimon N (2015) In vivo transcriptional activation using CRISPR/Cas9 in Drosophila. Genetics 201(2):433-442. https://doi.org/10.1534/genetics.115. 181065

Lin TS, Chen B, Chiang YM, Wang CCC (2019) Discovery and elucidation of the biosynthesis of aspernidgulenes: novel polyenes from Aspergillus nidulans by using serial promoter replacement. ChemBioChem 20(3):329-334. https://doi.org/10.1002/cbic. 201800486

Livak KJ, Schmittgen TD (2001) Analysis of relative gene expression data using real-time quantitative PCR and the 2(-Delta Delta C(T)) method. Methods 25(4):402-408. https://doi.org/10.1006/meth. 2001.1262
Lo HC, Entwistle R, Guo CJ, Ahuja M, Szewczyk E, Hung JH, Chiang YM, Oakley BR, Wang CC (2012) Two separate gene clusters encode the biosynthetic pathway for the meroterpenoids austinol and dehydroaustinol in Aspergillus nidulans. J Am Chem Soc 134(10): 4709-4720. https://doi.org/10.1021/ja209809t

Lyu HN, Liu HW, Keller NP, Yin WB (2020) Harnessing diverse transcriptional regulators for natural product discovery in fungi. Nat Prod Rep 37(1):6-16. https://doi.org/10.1039/c8np00027a

Ma H, Tu LC, Naseri A, Huisman M, Zhang S, Grunwald D, Pederson T (2016) CRISPR-Cas9 nuclear dynamics and target recognition in living cells. J Cell Biol 214(5):529-537. https://doi.org/10.1083/ jcb. 201604115

MacCabe AP, van Liempt H, Palissa H, Unkles SE, Riach MB, Pfeifer E, von Döhren H, Kinghorn JR (1991) Delta-(L-cu-Aminoadipyl)-Lcysteinyl-D-valine synthetase from Aspergillus nidulans. Molecular characterization of the $a c v A$ gene encoding the first enzyme of the penicillin biosynthetic pathway. J Biol Chem 266(19):12646-12654

Macheleidt J, Mattern DJ, Fischer J, Netzker T, Weber J, Schroeckh V, Valiante V, Brakhage AA (2016) Regulation and role of fungal secondary metabolites. Annu Rev Genet 50:371-392. https://doi. org/10.1146/annurev-genet-120215-035203

Mao Y, Chen C (2019) The hap complex in yeasts: structure, assembly mode, and gene regulation. Front Microbiol 10:1645. https://doi. org/10.3389/fmicb.2019.01645

McCluskey K, Wiest A, Plamann M (2010) The fungal genetics stock center: a repository for 50 years of fungal genetics research. J Biosci 35(1):119-126. https://doi.org/10.1007/s12038-010-0014-6

Medema MH, Blin K, Cimermancic P, de Jager V, Zakrzewski P, Fischbach MA, Weber T, Takano E, Breitling R (2011) antiSMASH: rapid identification, annotation and analysis of secondary metabolite biosynthesis gene clusters in bacterial and fungal genome sequences. Nucleic Acids Res 39(Web Server issue): W339-W346. https://doi.org/10.1093/nar/gkr466

Mingot JM, Espeso EA, Diez E, Penalva MA (2001) Ambient pH signaling regulates nuclear localization of the Aspergillus nidulans PacC transcription factor. Mol Cell Biol 21(5):1688-1699. https:// doi.org/10.1128/MCB.21.5.1688-1699.2001

Mooney JL, Yager LN (1990) Light is required for conidiation in Aspergillus nidulans. Genes Dev 4(9):1473-1482. https://doi.org/ 10.1101/gad.4.9.1473

Muro-Pastor MI, Gonzalez R, Strauss J, Narendja F, Scazzocchio C (1999) The GATA factor AreA is essential for chromatin remodelling in a eukaryotic bidirectional promoter. EMBO J 18(6):1584 1597. https://doi.org/10.1093/emboj/18.6.1584

Nayak T, Szewczyk E, Oakley CE, Osmani A, Ukil L, Murray SL, Hynes MJ, Osmani SA, Oakley BR (2006) A versatile and efficient genetargeting system for Aspergillus nidulans. Genetics 172(3):15571566. https://doi.org/10.1534/genetics.105.052563

Niehaus EM, Munsterkotter M, Proctor RH, Brown DW, Sharon A, Idan Y, Oren-Young L, Sieber CM, Novak O, Pencik A, Tarkowska D, Hromadova K, Freeman S, Maymon M, Elazar M, Youssef SA, ElShabrawy ES, Shalaby AB, Houterman P, Brock NL, Burkhardt I, Tsavkelova EA, Dickschat JS, Galuszka P, Guldener U, Tudzynski B (2016a) Comparative "Omics" of the Fusarium fujikuroi species complex highlights differences in genetic potential and metabolite synthesis. Genome Biol Evol 8(11):3574-3599. https://doi.org/10. 1093/gbe/evw259

Niehaus EM, Studt L, von Bargen KW, Kummer W, Humpf HU, Reuter G, Tudzynski B (2016b) Sound of silence: the beauvericin cluster in Fusarium fujikuroi is controlled by cluster-specific and global regulators mediated by H3K27 modification. Environ Microbiol 18(11):4282-4302. https://doi.org/10.1111/1462-2920.13576

Nielsen JC, Grijseels S, Prigent S, Ji B, Dainat J, Nielsen KF, Frisvad JC, Workman M, Nielsen J (2017) Global analysis of biosynthetic gene clusters reveals vast potential of secondary metabolite production in 
Penicillium species. Nat Microbiol 2:17044. https://doi.org/10. 1038/nmicrobiol.2017.44

Nikolov DB, Burley SK (1997) RNA polymerase II transcription initiation: a structural view. Proc Natl Acad Sci U S A 94(1):15-22. https://doi.org/10.1073/pnas.94.1.15

Nødvig CS, Nielsen JB, Kogle ME, Mortensen UH (2015) A CRISPRCas9 system for genetic engineering of filamentous fungi. PLoS One 10(7):e0133085. https://doi.org/10.1371/journal.pone.0133085

Nødvig CS, Hoof JB, Kogle ME, Jarczynska ZD, Lehmbeck J, Klitgaard DK, Mortensen UH (2018) Efficient oligo nucleotide mediated CRISPR-Cas9 gene editing in Aspergilli. Fungal Genet Biol 115: 78-89. https://doi.org/10.1016/j.fgb.2018.01.004

Nordberg H, Cantor M, Dusheyko S, Hua S, Poliakov A, Shabalov I, Smirnova T, Grigoriev IV, Dubchak I (2014) The genome portal of the Department of Energy Joint Genome Institute: 2014 updates. Nucleic Acids Res 42(Database issue):D26-D31. https://doi.org/ 10.1093/nar/gkt1069

Nützmann HW, Reyes-Dominguez Y, Scherlach K, Schroeckh V, Horn F, Gacek A, Schumann J, Hertweck C, Strauss J, Brakhage AA (2011) Bacteria-induced natural product formation in the fungus Aspergillus nidulans requires Saga/Ada-mediated histone acetylation. Proc Natl Acad Sci U S A 108(34):14282-14287. https://doi. org/10.1073/pnas.1103523108

Oakley CE, Ahuja M, Sun WW, Entwistle R, Akashi T, Yaegashi J, Guo CJ, Cerqueira GC, Russo Wortman J, Wang CC, Chiang YM, Oakley BR (2017) Discovery of McrA, a master regulator of Aspergillus secondary metabolism. Mol Microbiol 103(2):347365. https://doi.org/10.1111/mmi.13562

Pachlinger R, Mitterbauer R, Adam G, Strauss J (2005) Metabolically independent and accurately adjustable Aspergillus sp. expression system. Appl Environ Microbiol 71(2):672-678. https://doi.org/10. 1128/AEM.71.2.672-678.2005

Palmer JM, Keller NP (2010) Secondary metabolism in fungi: does chromosomal location matter? Curr Opin Microbiol 13(4):431-436. https://doi.org/10.1016/j.mib.2010.04.008

Piovesan A, Pelleri MC, Antonaros F, Strippoli P, Caracausi M, Vitale L (2019) On the length, weight and GC content of the human genome. BMC Res Notes 12(1):106. https://doi.org/10.1186/s13104-0194137-z

Ran FA, Hsu PD, Wright J, Agarwala V, Scott DA, Zhang F (2013) Genome engineering using the CRISPR-Cas9 system. Nat Protoc 8(11):2281-2308. https://doi.org/10.1038/nprot.2013.143

Rebordinos L, Vallejo I, Santos M, Collado IG, Carbu M, Cantoral JM (2000) Genetic analysis and relationship to pathogenicity in Botrytis cinerea. Rev Iberoam Micol 17(1):S37-S42

Reyes-Dominguez Y, Bok JW, Berger H, Shwab EK, Basheer A, Gallmetzer A, Scazzocchio C, Keller N, Strauss J (2010) Heterochromatic marks are associated with the repression of secondary metabolism clusters in Aspergillus nidulans. Mol Microbiol 76(6):1376-1386. https://doi.org/10.1111/j.1365-2958.2010. 07051.x

Romsdahl J, Wang CCC (2019) Recent advances in the genome mining of Aspergillus secondary metabolites (covering 2012-2018). Medchemcomm 10(6):840-866. https://doi.org/10.1039/ c9md00054b

Sanchez JF, Chiang YM, Szewczyk E, Davidson AD, Ahuja M, Elizabeth Oakley C, Woo Bok J, Keller N, Oakley BR, Wang CC (2010) Molecular genetic analysis of the orsellinic acid/F9775 gene cluster of Aspergillus nidulans. Mol BioSyst 6(3):587-593. https:// doi.org/10.1039/b904541d

Sanchez JF, Entwistle R, Hung JH, Yaegashi J, Jain S, Chiang YM, Wang CC, Oakley BR (2011) Genome-based deletion analysis reveals the prenyl xanthone biosynthesis pathway in Aspergillus nidulans. J Am Chem Soc 133(11):4010-4017. https://doi.org/10. 1021/ja1096682
Sanchez JF, Entwistle R, Corcoran D, Oakley BR, Wang CC (2012) Identification and molecular genetic analysis of the cichorine gene cluster in Aspergillus nidulans. Med Chem Commun 3:997-1002. https://doi.org/10.1039/C2MD20055D

Sarkari P, Marx H, Blumhoff ML, Mattanovich D, Sauer M, Steiger MG (2017) An efficient tool for metabolic pathway construction and gene integration for Aspergillus niger. Bioresour Technol 245(Pt B):1327-1333. https://doi.org/10.1016/j.biortech.2017.05.004

Scherlach K, Sarkar A, Schroeckh V, Dahse HM, Roth M, Brakhage AA, Horn U, Hertweck C (2011) Two induced fungal polyketide pathways converge into antiproliferative spiroanthrones. Chembiochem 12(12):1836-1839. https://doi.org/10.1002/cbic.201100132

Schinko T, Berger H, Lee W, Gallmetzer A, Pirker K, Pachlinger R, Buchner I, Reichenauer T, Güldener U, Strauss J (2010) Transcriptome analysis of nitrate assimilation in Aspergillus nidulans reveals connections to nitric oxide metabolism. Molecular Microbiology 78(3):720-738

Schmidtmann E, Anton T, Rombaut P, Herzog F, Leonhardt H (2016) Determination of local chromatin composition by CasID. Nucleus 7(5):476-484. https://doi.org/10.1080/19491034.2016.1239000

Schmitz ML, Baeuerle PA (1991) The p65 subunit is responsible for the strong transcription activating potential of NF- KB. EMBO J 10(12): 3805-3817. https://doi.org/10.1002/j.1460-2075.1991.tb04950.x

Schroeckh V, Scherlach K, Nützmann HW, Shelest E, Schmidt-Heck W, Schuemann J, Martin K, Hertweck C, Brakhage AA (2009) Intimate bacterial-fungal interaction triggers biosynthesis of archetypal polyketides in Aspergillus nidulans. Proc Natl Acad Sci U S A 106(34):14558-14563. https://doi.org/10.1073/pnas.0901870106

Schumacher J (2012) Tools for Botrytis cinerea: new expression vectors make the gray mold fungus more accessible to cell biology approaches. Fungal Genet Biol 49(6):483-497. https://doi.org/10. 1016/j.fgb.2012.03.005

Shimizu T, Ito T, Kanematsu S (2012) Transient and multivariate system for transformation of a fungal plant pathogen, Rosellinia necatrix, using autonomously replicating vectors. Curr Genet 58(3):129-138. https://doi.org/10.1007/s00294-012-0370-x

Shwab EK, Bok JW, Tribus M, Galehr J, Graessle S, Keller NP (2007) Histone deacetylase activity regulates chemical diversity in Aspergillus. Eukaryot Cell 6(9):1656-1664. https://doi.org/10. 1128/EC.00186-07

Sigma-Aldrich (2020) Protocol for annealing oligonucleotides. Publisher. https://shar.es/a3kMkV Accessed 21.01.2020 2020

Song R, Zhai Q, Sun L, Huang E, Zhang Y, Zhu Y, Guo Q, Tian Y, Zhao $\mathrm{B}, \mathrm{Lu} \mathrm{H}$ (2019) CRISPR/Cas9 genome editing technology in filamentous fungi: progress and perspective. Appl Microbiol Biotechnol 103(17):6919-6932. https://doi.org/10.1007/s00253019-10007-w

Soutourina J (2018) Transcription regulation by the mediator complex. Nat Rev Mol Cell Biol 19(4):262-274. https://doi.org/10.1038/nrm. 2017.115

Studt L, Schmidt FJ, Jahn L, Sieber CM, Connolly LR, Niehaus EM, Freitag M, Humpf HU, Tudzynski B (2013) Two histone deacetylases, FfHda1 and FfHda2, are important for Fusarium fujikuroi secondary metabolism and virulence. Appl Environ Microbiol 79(24):7719-7734. https://doi.org/10.1128/AEM. 01557-13

Studt L, Rosler SM, Burkhardt I, Arndt B, Freitag M, Humpf HU, Dickschat JS, Tudzynski B (2016) Knock-down of the methyltransferase Kmt6 relieves $\mathrm{H} 3 \mathrm{~K} 27 \mathrm{me} 3$ and results in induction of cryptic and otherwise silent secondary metabolite gene clusters in Fusarium fujikuroi. Environ Microbiol 18(11):4037-4054. https://doi.org/10. $1111 / 1462-2920.13427$

Sulyok M, Stadler D, Steiner D, Krska R (2020) Validation of an LC-MS/ MS-based dilute-and-shoot approach for the quantification of $>500$ mycotoxins and other secondary metabolites in food crops: 
challenges and solutions. Anal Bioanal Chem 412:2607-2620. https://doi.org/10.1007/s00216-020-02489-9

Sung CT, Chang SL, Entwistle R, Ahn G, Lin TS, Petrova V, Yeh HH, Praseuth MB, Chiang YM, Oakley BR, Wang CCC (2017) Overexpression of a three-gene conidial pigment biosynthetic pathway in Aspergillus nidulans reveals the first NRPS known to acetylate tryptophan. Fungal Genet Biol 101:1-6. https://doi.org/10. 1016/j.fgb.2017.01.006

Szewczyk E, Chiang YM, Oakley CE, Davidson AD, Wang CC, Oakley BR (2008) Identification and characterization of the asperthecin gene cluster of Aspergillus nidulans. Appl Environ Microbiol 74(24):7607-7612. https://doi.org/10.1128/AEM.01743-08

Then Bergh K, Brakhage AA (1998) Regulation of the Aspergillus nidulans penicillin biosynthesis gene $a c v A(p c b A B)$ by amino acids: implication for involvement of transcription factor PACC. Appl Environ Microbiol 64(3):843-849

Tilburn J, Scazzocchio C, Taylor GG, Zabicky-Zissman JH, Lockington RA, Davies RW (1983) Transformation by integration in Aspergillus nidulans. Gene 26(2-3):205-221. https://doi.org/10. 1016/0378-1119(83)90191-9

Tilburn J, Sarkar S, Widdick DA, Espeso EA, Orejas M, Mungroo J, Penalva MA, Arst HN Jr (1995) The Aspergillus PacC zinc finger transcription factor mediates regulation of both acid- and alkalineexpressed genes by ambient pH. EMBO J 14(4):779-790

Watanabe A, Fujii I, Sankawa U, Mayorga ME, Timberlake WE, Ebizuka Y (1999) Re-identification of Aspergillus nidulans wA gene to code for a polyketide synthase of naphthopyrone. Tetrahedron Lett 40(1): 91-94. https://doi.org/10.1016/s0040-4039(98)80027-0

Weitzman JB (2002) The mouse genome. Genome Biol 3, spotlight20021205-02 (2002). https://doi.org/10.1186/gb-spotlight20021205-02

Weld RJ, Plummer KM, Carpenter MA, Ridgway HJ (2006) Approaches to functional genomics in filamentous fungi. Cell Res 16(1):31-44. https://doi.org/10.1038/sj.cr.7310006

Westphal KR, Muurmann AT, Paulsen IE, Norgaard KTH, Overgaard ML, Dall SM, Aalborg T, Wimmer R, Sorensen JL, Sondergaard TE (2018) Who needs neighbors? PKS8 is a stand-alone gene in Fusarium graminearum responsible for production of gibepyrones and prolipyrone B. Molecules 23(9):2232. https://doi.org/10.3390/ molecules 23092232

Westphal KR, Nielsen KAH, Wollenberg RD, Mollehoj MB, Bachleitner S, Studt L, Lysoe E, Giese H, Wimmer R, Sorensen JL, Sondergaard TE (2019) Fusaoctaxin A, an example of a two-step mechanism for non-ribosomal peptide assembly and maturation in fungi. Toxins (Basel) 11(5):277. https://doi.org/10.3390/toxins11050277

Wiemann P, Sieber CM, von Bargen KW, Studt L, Niehaus EM, Espino JJ, Huss K, Michielse CB, Albermann S, Wagner D, Bergner SV,
Connolly LR, Fischer A, Reuter G, Kleigrewe K, Bald T, Wingfield BD, Ophir R, Freeman S, Hippler M, Smith KM, Brown DW, Proctor RH, Münsterkötter M, Freitag M, Humpf HU, Güldener U, Tudzynski B (2013) Deciphering the cryptic genome: genomewide analyses of the rice pathogen Fusarium fujikuroi reveal complex regulation of secondary metabolism and novel metabolites. PLoS Pathog 9(6):e1003475. https://doi.org/10.1371/journal.ppat. 1003475

Wiemann P, Soukup AA, Folz JS, Wang PM, Noack A, Keller NP (2018) CoIN: co-inducible nitrate expression system for secondary metabolites in Aspergillus nidulans. Fungal Biol Biotechnol 5:6. https:// doi.org/10.1186/s40694-018-0049-2

Winston F, Dollard C, Ricupero-Hovasse SL (1995) Construction of a set of convenient Saccharomyces cerevisiae strains that are isogenic to S288C. Yeast 11(1):53-55. https://doi.org/10.1002/yea.320110107

Yadon AN, Van de Mark D, Basom R, Delrow J, Whitehouse I, Tsukiyama T (2010) Chromatin remodeling around nucleosomefree regions leads to repression of noncoding RNA transcription. Mol Cell Biol 30(21):5110-5122. https://doi.org/10.1128/MCB. 00602-10

Yaegashi J, Praseuth MB, Tyan SW, Sanchez JF, Entwistle R, Chiang YM, Oakley BR, Wang CC (2013) Molecular genetic characterization of the biosynthesis cluster of a prenylated isoindolinone alkaloid aspernidine A in Aspergillus nidulans. Org Lett 15(11):28622865. https://doi.org/10.1021/ol401187b

Yeh HH, Chiang YM, Entwistle R, Ahuja M, Lee KH, Bruno KS, Wu TK, Oakley BR, Wang CC (2012) Molecular genetic analysis reveals that a nonribosomal peptide synthetase-like (NRPS-like) gene in Aspergillus nidulans is responsible for microperfuranone biosynthesis. Appl Microbiol Biotechnol 96(3):739-748. https://doi.org/ 10.1007/s00253-012-4098-9

Yeh HH, Ahuja M, Chiang YM, Oakley CE, Moore S, Yoon O, Hajovsky H, Bok JW, Keller NP, Wang CC, Oakley BR (2016) Resistance gene-guided genome mining: serial promoter exchanges in Aspergillus nidulans reveal the biosynthetic pathway for fellutamide B, a proteasome inhibitor. ACS Chem Biol 11(8): 2275-2284. https://doi.org/10.1021/acschembio.6b00213

Yuan GC, Liu YJ, Dion MF, Slack MD, Wu LF, Altschuler SJ, Rando OJ (2005) Genome-scale identification of nucleosome positions in S. cerevisiae. Science 309(5734):626-630. https://doi.org/10.1126/ science. 1112178

Publisher's note Springer Nature remains neutral with regard to jurisdictional claims in published maps and institutional affiliations. 